\title{
A Toll-like receptor 2 agonist-fused antigen enhanced anti- tumor immunity by increasing antigen presentation and the CD8 memory $T$ cells population
}

\author{
Chiao-Chieh Wu ${ }^{1,2}$, Shih-Jen Liu' ${ }^{2,3}$, Hsin-Wei Chen ${ }^{2,3}$, Kuan-Yin Shen ${ }^{2}$, Chih-Hsiang \\ Leng ${ }^{1,2,3}$ \\ ${ }^{1}$ Graduate Institute of Life Sciences, National Defense Medical Center, Taipei 114, Taiwan \\ ${ }^{2}$ National Institute of Infectious Disease and Vaccinology, National Health Research Institutes, Miaoli County 350, Taiwan \\ ${ }^{3}$ Graduate Institute of Immunology, China Medical University, Taichung 40402, Taiwan
}

Correspondence to: Chih-Hsiang Leng, e-mail: leoleng@nhri.org.tw

Keywords: rlipo-immunogen, Toll-like receptor 2, antigen presentation, tumor regression, memory $T$ cells

Received: October 21, $2015 \quad$ Accepted: March 31, $2016 \quad$ Published: April 26, 2016

\section{ABSTRACT}

The induction of long-lived effector $\mathrm{CDB}^{+} \mathrm{T}$ cells is key to the development of efficient cancer vaccines. In this study, we demonstrated that a Toll-like receptor 2 (TLR2) agonist-fused antigen increased antigen presentation via TLR2 signaling and induced effector memory-like $\mathrm{CDB}^{+} \mathrm{T}$ cells against cancer after immunization. The $\mathrm{N}$-terminus of ovalbumin (OVA) was biologically fused with a bacterial lipid moiety TLR2 agonist to produce a recombinant lipidated ovalbumin (rlipo-OVA). We demonstrated that rlipo-OVA activated bone marrow-derived dendritic cells (BM-DCs) maturation and increased antigen presentation by major histocompatibility complex (MHC) class I via TLR2. After immunization, rlipo-OVA skewed the immune response towards T helper (Th) 1 and induced OVA-specific cytotoxic T lymphocyte (CTL) responses. Moreover, immunization with rlipo-OVA induced higher numbers of effector memory (CD44 ${ }^{+} \mathrm{CD}^{2} \mathrm{~L}^{-}$) $\mathrm{CD8}^{+} \mathrm{T}$ cells compared with recombinant ovalbumin (rOVA) alone or rOVA mixed with the TLR2 agonist Pam3CSK4. Accordingly, the CD27+CD43+ effector memory $\mathrm{CDB}^{+} \mathrm{T}$ cells expressed high levels of the long-lived CD127 marker. The administration of rlipo-OVA could inhibit tumor growth, but the anti-tumor effects were lost after the depletion of CD8 or CD127 cells in vivo. These findings suggested that the TLR2 agonist-fused antigen induced long-lived memory $\mathrm{CD8}^{+} \mathrm{T}$ cells for efficient cancer therapy.

\section{INTRODUCTION}

Cancer vaccines are designed to prevent cancer formation or eliminate cancer cells. To eliminate cancer cells, the induction of antigen-specific $\mathrm{CD}^{+} \mathrm{T}$ cells with cytolytic activity capable of killing cancer cells is critical [1]. Although many different cancer vaccine approaches have been tested in cancer patients, their therapeutic efficacy is still limited. Recently, the quantity and quality of antigen-specific cytotoxic $\mathrm{T}$ lymphocytes (CTLs) have been proposed to play an important role in their therapeutic effects [2]. After priming by antigenpresenting cells (APCs), $\mathrm{CD}^{+} \mathrm{T}$ cells present an antigenic peptide on major histocompatibility complex (MHC) class I molecules. Subsequently, the primed antigen-specific $\mathrm{CD}^{+} \mathrm{T}$ cells undergo clonal expansion, resulting in the contraction of effector cells and the establishment of memory cells [3]. The induction of long-lived memory cells is considered an important factor in efficient antitumor immunity. Ideally, a cancer vaccine should skew the $\mathrm{T}$ cell response to $\mathrm{T}$ helper (Th) 1 responses that facilitate the production of potent CTLs and memory $\mathrm{CD} 8^{+} \mathrm{T}$ cells $[1,4,5]$.

Protein-based immunogens as cancer vaccines have low toxicity and a very good safety profile. However, the immunogenicity of protein immunogens is low, particularly for the induction of CTL responses [6]. Typically, exogenous protein immunogens are taken up and digested into small peptides for presentation by MHC class II molecules on APCs to prime $\mathrm{CD} 4^{+} \mathrm{T}$ cells. Additionally, certain proteins can be processed and crosspresented by the MHC class I pathway for $\mathrm{CD} 8^{+} \mathrm{T}$ cell 
priming [7, 8]. Different approaches have been reported to increase the cross-presentation of protein immunogens, such as Toll-like receptor (TLR) agonists [9-11]. Moreover, innate receptor agonists have been shown to increase the cross-presentation of exogenous antigens [12-14]. In our previous study, we showed that TLR2 agonist-fused peptides could be cross-presented to $\mathrm{CD} 8^{+}$ $\mathrm{T}$ cells via a Rab7-regulated endosomal pathway [15]. These innate receptor agonists not only activated APCs to express co-stimulatory molecules but also increased antigen presentation. Therefore, the co-delivery of innate receptor agonists and antigens is an important approach to prime CTL responses. Recently, TLRs were also found to be capable of inducing important specialized groups of memory $\mathrm{T}$ cells [3]. Memory $\mathrm{CD} 8^{+} \mathrm{T}$ cells can be divided into two major subsets: effector memory $\mathrm{T}$ cells $\left(\mathrm{T}_{\mathrm{EM}}\right)$ and central memory $\mathrm{T}$ cells $\left(\mathrm{T}_{\mathrm{CM}}\right)$. In humans, $\mathrm{T}_{\mathrm{EM}}$ $\left(\mathrm{CD} 62 \mathrm{~L}^{\mathrm{lo}} \mathrm{CCR} 7^{10}\right)$ cells are defined by their lack of lymph node-homing molecules that are capable of immediate effector functions; these cells are different from $T_{C M}$ $\left(\mathrm{CD} 62 \mathrm{~L}^{\text {hi }} \mathrm{CCR} 7^{\text {hi }}\right)$ cells that express lymph node-homing molecules and are specialized for the proliferation of effector functions upon reinfection [16, 17]. In mice, CD44 is a conservative marker expressed at high levels on the surface of all memory $\mathrm{T}$ cells, irrespective of their activation status $[18,19]$. Phenotypic features could also be defined using a homing molecule such as CD62L, resulting in identification of the $\mathrm{T}_{\mathrm{EM}}\left(\mathrm{CD} 44^{\text {high }} \mathrm{CD} 62 \mathrm{~L}^{\text {low }}\right)$ and $\mathrm{T}_{\mathrm{CM}}\left(\mathrm{CD} 44^{\text {high }} \mathrm{CD} 62 \mathrm{~L}^{\text {high }}\right)$ cell subsets. However, Hikono et al. reported that both expression of CD27 and CD43 which are required for generating long-term maintenance of $\mathrm{T}$ cell immunity and more closely related to their functions on phenotypic memory $\mathrm{CD}^{+} \mathrm{T}$ cells, respectively. The $\mathrm{CD} 27^{\text {high }} \mathrm{CD} 43^{\text {low }}$ cell subset showed optimal recall proliferation and superior functions [20-24]. Moreover, CD127 expression was use to characterize longlived memory $\mathrm{T}$ cells [25]. Generally, $\mathrm{CD} 8^{+} \mathrm{T}$ cells with a functionally good memory express high levels of CD127 and CD27 and low levels of CD43 [26-28]. Therefore, identifying novel methods to direct the differentiation of antigen-specific $\mathrm{CD} 8^{+} \mathrm{T}$ cells into functional longlived memory $\mathrm{CD}^{+} \mathrm{T}$ cells is critical for efficient cancer immunotherapy. Previously, we established a platform for the high-yield production of recombinant lipoproteins $[29,30]$ that were TLR2 agonist-fused proteins. The lipid moiety of the recombinant lipoprotein differs from that of synthetic tri-acylated lipopeptides [31]. This distinction enables the recombinant lipoprotein to elicit different immune responses compared with the synthetic lipopeptide, resulting in the induction of different levels of biological cytokines and chemokines [32]. Additionally, we demonstrated that recombinant lipidated human papillomavirus (HPV) E7 induced CTLs and provided potential protective immunity against cervical cancer in a mouse model [33]. In this report, we used ovalbumin (OVA) as a model immunogen to demonstrate that lipidated immunogens can be efficiently cross-presented to $\mathrm{CD} 8^{+} \mathrm{T}$ cells and induce high-quality memory $\mathrm{CD} 8^{+}$ $\mathrm{T}$ cells. Importantly, depletion of $\mathrm{CD} 127^{+} \mathrm{T}$ cells led to the loss of the anti-tumor effects of the recombinant lipoimmunogen. Thus, $\mathrm{CD} 127^{+}$cells are necessary for anti-tumor immunity.

\section{RESULTS}

\section{Production and characterization of recombinant ovalbumin (rOVA) and recombinant lipidated ovalbumin (rlipo-OVA)}

Following our previous procedure, the ovalbumin (OVA) gene was cloned into the expression vector with and without the lipid signal peptide to construct the plasmids pLOVA and pOVA for the expression of rlipo-OVA and rOVA, respectively [29]. The recombinant antigens were engineered to contain a hexahistidine tag (HisTag) at their C-terminus and expressed in an Escherichia coli system under the control of the T7 promoter (Figure 1A). rOVA was purified from the lysates using immobilized metal affinity chromatography (IMAC) and polished using anion-exchange chromatography (Figure 1B, lanes 1-5). The purified protein was analyzed by immunoblotting with an anti-His tag antibody (Figure 1B, lanes 6-10). rlipo-OVA was purified using IMAC (Figure 1B, lanes 11-14). The recombinant protein was detected with an anti-His tag antibody (Figure 1B, lanes 15-18).

rlipo-OVA and rOVA were digested with trypsin to monitor their peptide mass fingerprinting (PMF) by MALDI-TOF mass spectrometry. The results confirmed that the major peaks in the mass spectra corresponded to $\mathrm{m} / \mathrm{z}$ values derived from rlipo-OVA and rOVA (data not shown). The identification of the lipid moiety in rlipo-OVA was similar to our previous reports $[29,31]$. Briefly, the $\mathrm{N}$-terminal fragments from the digested rlipo-OVA were purified and identified using mass spectrometry. Three peaks with $\mathrm{m} / \mathrm{z}$ values of 1452,1466 and 1480 (Figure 1C) corresponded to the lipid-modified CSQEAK sequence. After the lipopolysaccharide (LPS) was removed (less than $0.01 \mathrm{EU} / \mathrm{mg}$ ), purified rlipo-OVA, rOVA and OVA from egg whites were comparatively analyzed for their immunogenicity and efficacy in animal models.

\section{Bone marrow-derived dendritic cells (BM-DCs) were activated by rlipo-OVA via TLR2}

Splenocytes were isolated and stimulated with recombinant immunogens and positive control reagents (LPS and Pam3 are TLR4 and TLR2 agonists, respectively) to determine the proliferative responses. The results showed that rlipo-OVA stimulated the proliferation of splenocytes at concentrations of $10 \mathrm{ng} / \mathrm{ml}, 100 \mathrm{ng} /$ $\mathrm{ml}$ and $1000 \mathrm{ng} / \mathrm{ml}$. In contrast, OVA and rOVA failed to stimulate splenocyte proliferation (Figure 2A). To 
test their activity on the maturation of dendritic cells, BM-DCs were stimulated with rOVA and rlipo-OVA. The co-stimulatory molecules CD40 and CD80 were up-regulated by rlipo-OVA but not OVA or rOVA (Figure $2 \mathrm{~B}$ and $2 \mathrm{C}$ ). The secretion of TNF- $\alpha$ and IL-12p40 from BM-DCs was detected after stimulation with rlipo-OVA but not OVA and rOVA (Figure 2D and 2E). To exclude the effect of residual endotoxin in rlipo-OVA, polymyxin $\mathrm{B}$ (PMB) was mixed with the recombinant immunogens to stimulate BM-DCs. Our data showed that there were no significant effects on the stimulatory properties of rlipoOVA. These results confirmed that the activation of BMDCs by rlipo-OVA was due to the lipid moiety of rlipoOVA (Figure 2B-2E).

BM-DCs from wild-type (WT) and TLR2-knockout (TLR2KO) mice were employed to investigate whether rlipo-OVA activated BM-DCs via TLR2. Our results showed that rlipo-OVA and Pam3 stimulated the BM-DCs of WT mice, but not the TLR2KO mice, to secrete TNF- $\alpha$ (Figure 2F). These data demonstrated that rlipo-OVA activated BM-DCs via TLR2 signaling.

\section{BM-DCs pulsed with rlipo-OVA increased the presentation of OVA-H-2K ${ }^{\text {b }}$ via TLR2 signaling}

Because a TLR2 agonist-conjugated peptide could be taken up and used to activate $\mathrm{CD} 8^{+} \mathrm{T}$ cells [15], we investigated whether the presentation of peptide/MHC I complexes was indeed increased on the surface of dendritic cells. Peptide/MHC I complexes on antigen-pulsed BM-DCs were analyzed using the 25-D1.16 monoclonal antibody that recognized the SIINFEKL peptide $\left(\mathrm{OVA}_{257-264}\right)$ and $\mathrm{MHC}$ class I H-2 $\mathrm{K}^{\mathrm{b}}$ molecule complex (OVA-H-2 $\mathrm{K}^{\mathrm{b}}$ ). OVA-H-2 $\mathrm{K}^{\mathrm{b}}$ was increased in the rlipo-OVA-pulsed BM-DCs of WT mice but not in the rOVA-pulsed BM-DCs of WT mice. Moreover, the increased
A

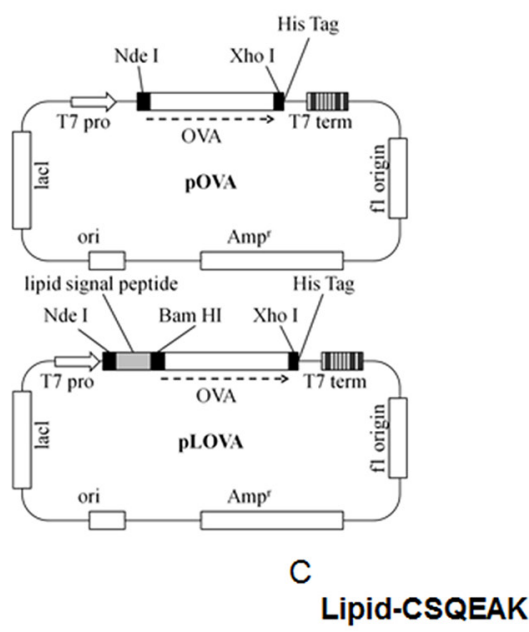

B rOVA

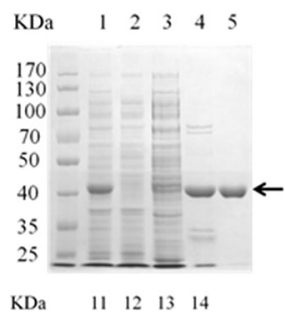

rlipo-OVA

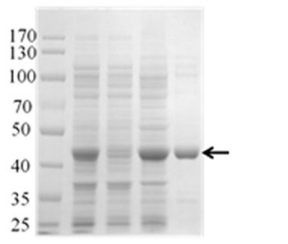

$\underline{1466.10}$

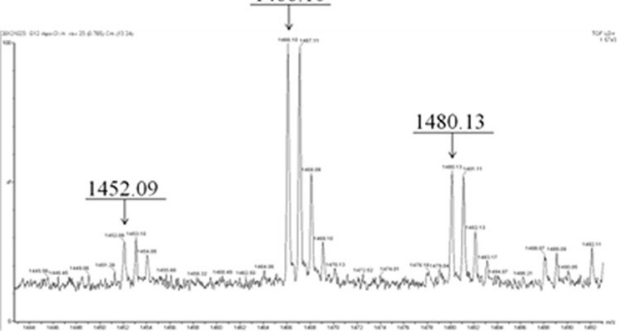

\section{Western blot}

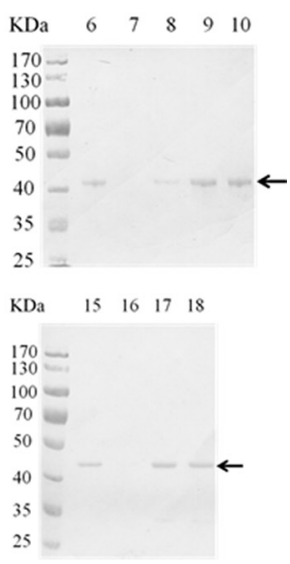

Figure 1: Construction, production and identification of rOVA and rlipo-OVA. (A) The plasmid maps of pOVA and pLOVA that express rOVA and rlipo-OVA, respectively. (B) The rOVA and rlipo-OVA protein purification process used 10\% reducing SDS-PAGE followed by Coomassie Blue staining and anti-HisTag antibodies for immunoblotting. The recombinant rOVA was expressed in the E. coli strain BL21 (DE3). Lane 1, rOVA expression after IPTG induction; lane 2, protein expression in the absence of IPTG induction; lane 3, rOVA extracted fraction; lane 4, recombinant rOVA purified by Ni-NTA resin; and lane 5, polished recombinant rOVA by Q sepharose resin. Lanes 6-10 show immunoblotting to monitor the process of rOVA purification; these lanes are the same as lanes 1-5, respectively. The recombinant rlipo-OVA was expressed in the E. coli strain C43 (DE3). Lane 11, rlipo-OVA expression after IPTG induction; lane 12, protein expression in the absence of IPTG induction; lane 13, rlipo-OVA extracted fraction; and lane 14, rlipo-OVA protein purified by Ni-NTA resin. Lanes 15-18 show immunoblotting to monitor the rlipo-OVA purification process; the samples in these lanes are the same as those in lanes 11-14, respectively. The arrows indicate the electrophoretic positions of rOVA or rlipo-OVA in the SDS gels or blots. (C) N-terminal rlipo-OVA fragments were obtained and identified after 3 days of digestion. The digested sample was analyzed on a Waters $^{\mathrm{R}}$ MALDI micro MX ${ }^{\mathrm{TM}}$ mass spectrometer. The MALDI-TOF MS spectra revealed lipid peptide signals with three $\mathrm{m} / \mathrm{z}$ value peaks of $1452.09,1466.10$, and 1480.13 . 
presentation of OVA-H-2 $\mathrm{K}^{\mathrm{b}}$ was lost or reduced on rlipoOVA-pulsed BM-DCs from the TLR2KO and myeloid differentiation primary response gene 88-knockout (MyD88KO) mice (Figure S1). Accordingly, OVA-H-2K ${ }^{\mathrm{b}}$ presentation was determined using different doses $(25,50$, $100 \mathrm{nM}$ ) of rlipo-OVA and rOVA-pulsed BM-DCs from the WT, TLR2KO and MyD88KO mice (Figure 3A). Additionally, the antigen presentation was assessed by $\mathrm{T}$ cell activation using $\left[{ }^{3} \mathrm{H}\right]$ thymidine incorporation (Figure 3B) and IFN- $\gamma$ (Figure 3C). The increased antigen presentation of the rlipo-OVA-pulsed BM-DCs could increase OT-1 cells proliferation and IFN- $\gamma$ secretion in WT mice but not TLR2KO and MyD88KO mice. These data corresponded with the SII/H-2K $\mathrm{K}^{\mathrm{b}}$ complexes formation that were detected as shown in the Figure $3 \mathrm{~A}$. These results directly showed that the lipidated immunogen indeed increased the presentation of peptide/ MHC I complexes on the surfaces of dendritic cells.

\section{OVA-specific $T$ cell responses were elicited by immunization with rlipo-OVA}

C57BL/6 mice were subcutaneously immunized at the base of the tail on days 0 and 7 with rlipo-OVA, rOVA and PBS to determine the OVA-specific CTL responses. The splenocytes of the immunized mice were stimulated with the OVA-specific peptide SIINFEKL (SII, OVA ${ }_{257-264}$ ) and the irrelevant peptide RAHYNIVTF (RAH, HPV 16 E7 ${ }_{49-57}$ ) to measure the number of OVA-specific IFN- $\gamma$ secreting cells using the ELISPOT assay (see Materials and Methods). The results showed that immunization with rlipo-OVA induced higher numbers of SII-specific
A

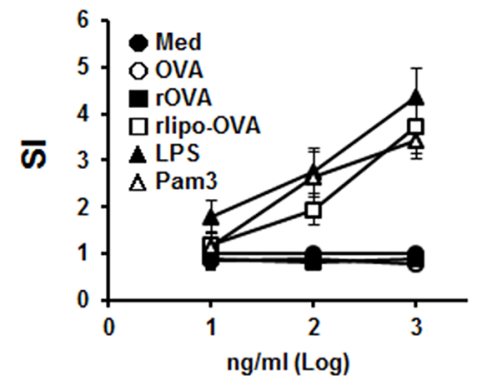

D

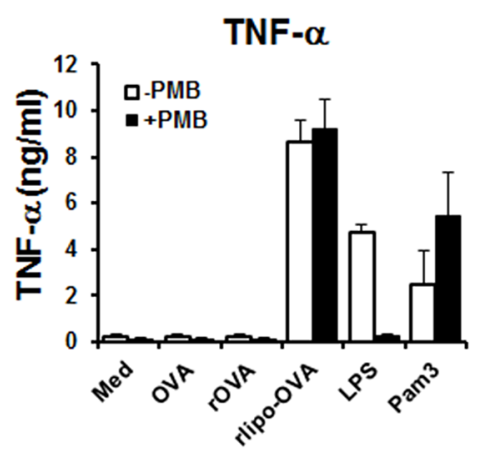

B

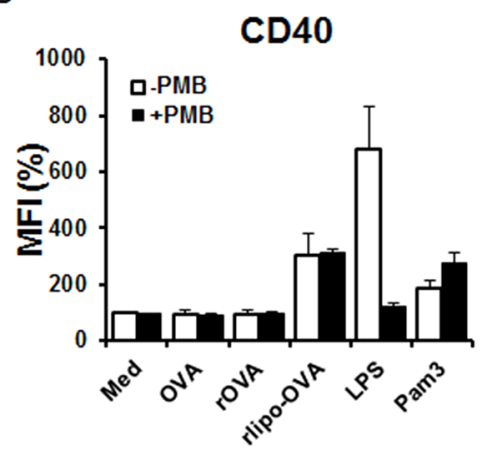

E

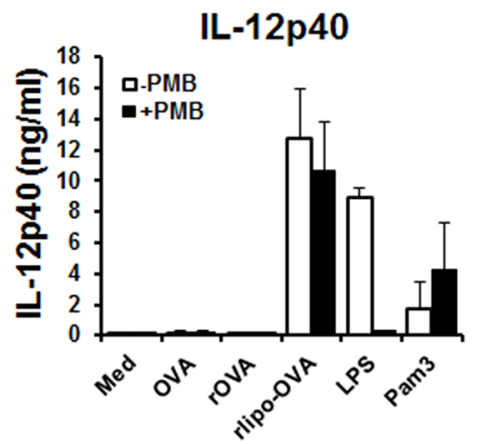

C

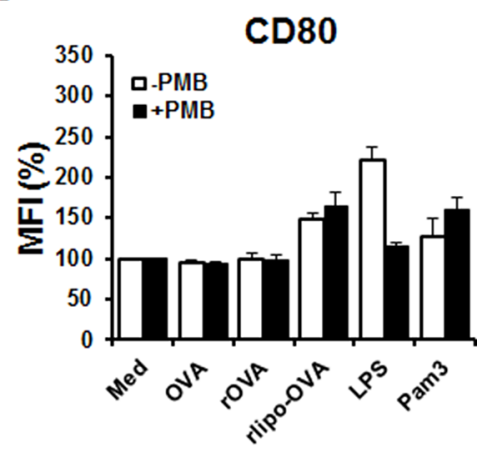

F

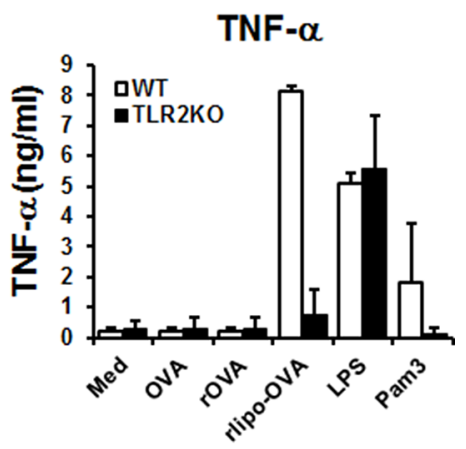

Figure 2: rlipo-OVA stimulates immune cell activation via TLR2. (A) Splenocytes were isolated from wild-type C57BL/6 mice and seeded at a density of $2.5 \times 10^{5}$ cells/well in 96-well cell culture plates. The cells were incubated with different concentrations of LPS (10-1000 ng/ml), Pam3 (10-1000 ng/ml), OVA (10-1000 ng/ml), rOVA (10-1000 ng/ml) or rlipo-OVA (10-1000 ng/ml) for 72 h. After $72 \mathrm{~h}, 10 \%$ CellTiter $96^{\circledR} \mathrm{AQ}_{\text {ueous }}$ One Solution Reagent was added to each well and the $\mathrm{OD}_{490}$ was measured. Stimulation index: $(\mathrm{SI})=\mathrm{OD}_{490}$ of the stimulated cells/ OD ${ }_{490}$ of the negative controls. The data represent the mean $\pm \mathrm{SD}$ of six animals. BM-DCs from wildtype mice were cultured in medium supplemented with LPS (100 ng/ml), Pam3 (100 nM), OVA (2.5 $\mu \mathrm{g} / \mathrm{ml}), \mathrm{rOVA}(2.5 \mu \mathrm{g} / \mathrm{ml})$ or rlipo-OVA $(2.5 \mu \mathrm{g} / \mathrm{ml})$ in the presence or absence of polymyxin B $(50 \mu \mathrm{g} / \mathrm{ml})$. After an 18 -h incubation, the dendritic cells were pre-gated on the CD11 $\mathrm{c}^{+}$cell population to measure the expression of the cell surface markers CD40 (B) and CD80 (C) by flow cytometry. The mean fluorescence intensity (MFI)\% for cells cultured in medium was defined as $100 \%$, and the independent experiments were performed in triplicate. For the inflammatory cytokine secretion studies, the supernatants were collected and analyzed for TNF- $\alpha$ (D) and IL-12 (p40) (E) production by ELISA. Three independent experiments were performed, and the data are presented as the mean + SD. (F) BM-DCs from WT or TLR2KO mice were cultured either in medium alone or in medium supplemented with LPS (100 ng/ml), Pam3 (100 nM), OVA $(2.5 \mu \mathrm{g} / \mathrm{ml})$, rOVA $(2.5 \mu \mathrm{g} / \mathrm{ml})$ or rlipo-OVA $(2.5 \mu \mathrm{g} / \mathrm{ml})$. After an 18-h incubation, the supernatants were collected and analyzed for TNF- $\alpha$ production by ELISA. The data are presented as the mean $+\mathrm{SD}, n=3$. 
INF- $\gamma$-secreting cells $(238.0 \pm 41.2)$ compared with rOVA $(22.7 \pm 9.8$; rOVA vs. rlipo-OVA, $p<0.001$; Figure 4A). We validated the OVA-specific IFN- $\gamma^{+} \mathrm{CD}^{+} \mathrm{T}$ cells using flow cytometry. The mice immunized with rlipo-OVA showed a significantly higher level of $\mathrm{CD}^{+}$SII-specific IFN- $\gamma$-producing $\mathrm{CD}^{+}$cells $(1316.4 \pm 452.0)$ compared with rOVA $(383.8 \pm 361.6$; rOVA vs. rlipo-OVA, $p<0.01$; Figure 4B).

To investigate the killing activity of $\mathrm{T}$ cells after the administration of rlipo-OVA and rOVA, the immunized mice were adoptively transferred with carboxyfluorescein diacetate succinimidyl ester (CFSE)-labeled and SIIpulsed cells for $18 \mathrm{~h}$. The CFSE-labeled cells could be monitored to evaluate the specific killing ability of the immunized mice. The results demonstrated that rlipo-OVA immunization induced a higher level of OVA-specific CTL activity in vivo than rOVA immunization (Figure 4C). The specific lysis were calculated as $2.03 \pm 3.51 \%, 6.23 \pm$ $5.80 \%$, and $61.72 \pm 21.25 \%$ in the PBS, rOVA and rlipoOVA immunized mice, respectively (rOVA vs. rlipo-OVA, $p<0.001$; Figure 4D). These results clearly demonstrated that immunization with the lipidated immunogen induced

A

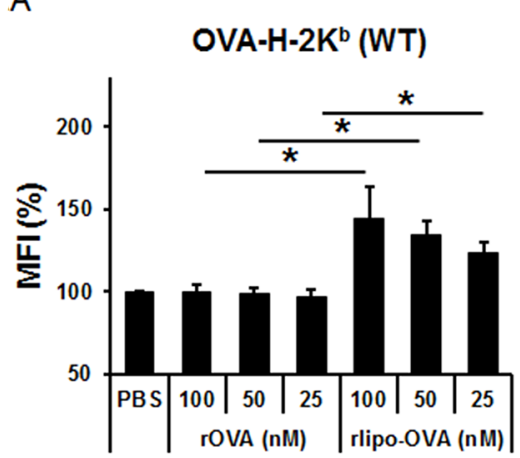

B

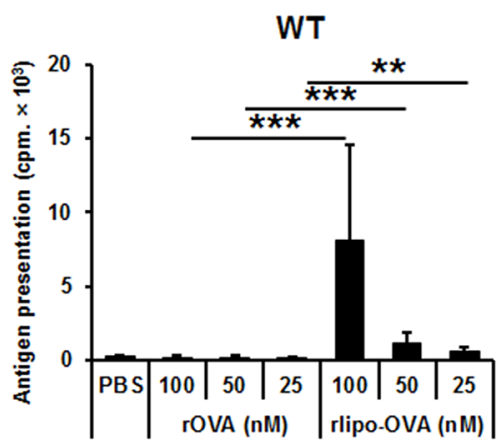

C

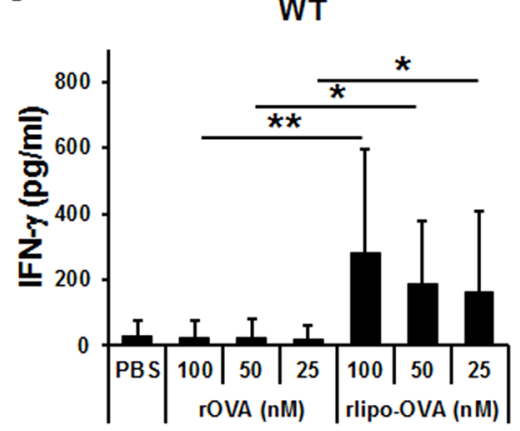

OVA-H-2K ${ }^{\mathrm{b}}$ (TLR2KO)

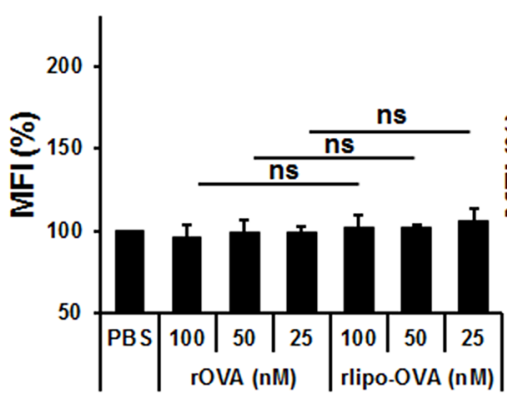

TLR2KO

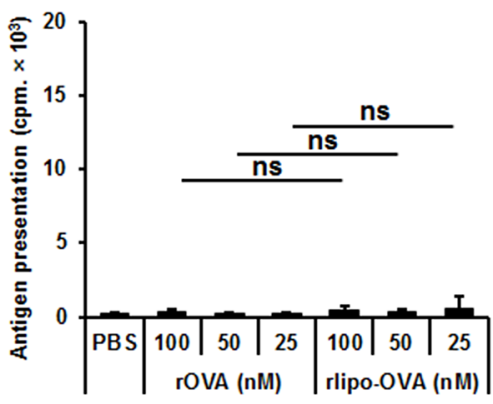

TLR2KO

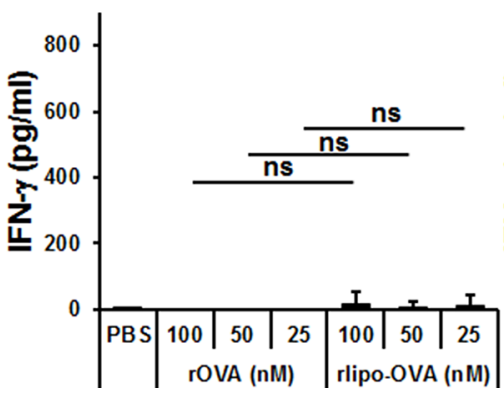

OVA-H-2K ${ }^{\mathrm{b}}$ (MyD88KO)

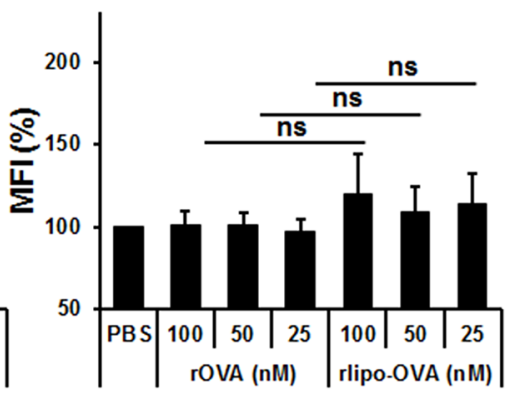

MyD88KO

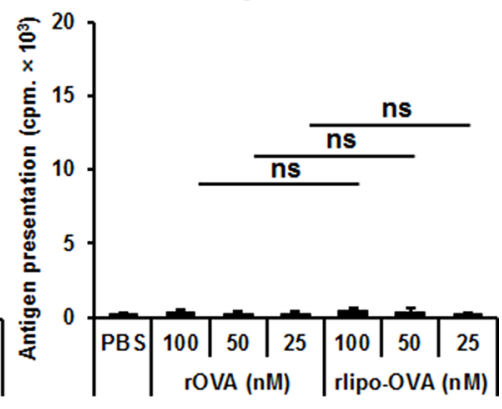

MyD88Ko

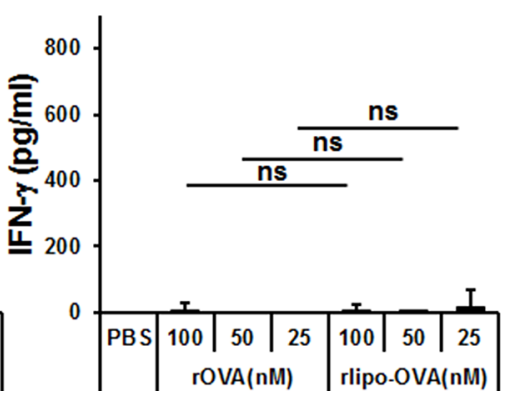

Figure 3: rlipo-OVA increases BM-DCs presenting the OVA-H-2K ${ }^{\mathrm{b}}$ molecule via TLR2 signaling. (A) BM-DCs from WT, TLR2KO and MyD88KO mice were incubated for $24 \mathrm{~h}$ with PBS, (100-25 nM) rOVA, or (100-25 nM) rlipo-OVA, and the OVAH-2K $\mathrm{K}^{\mathrm{b}}$ OVA-peptide were assessed by flow-cytometry analysis. Cells were stained with the PE-labeled 25-D1.16 antibody that recognizes OVA-derived SIINFEKL (SII) assembled with BM-DCs H-2K $\mathrm{K}^{\mathrm{b}}$. (B) Antigen presentation was determined by cell proliferation using a $\left[{ }^{3} \mathrm{H}\right]$ thymidine incorporation assay. The antigen-pulsed BM-DCs $\left(1 \times 10^{4}\right)$ were cultured with $1 \times 10^{5} \mathrm{CD} 8^{+} \mathrm{T}$ cells of OT- 1 mice for $72 \mathrm{~h}$. Average cpm incorporated in triplicate samples are shown $(+\mathrm{SD})$. (C) At 5 day after the antigen-pulsed BM-DCs were cultured with CD8 ${ }^{+}$ $\mathrm{T}$ cells of OT-1 mice, supernatant was collected and IFN- $\gamma$ was measured using ELISA. The data are expressed as the means + SD from three independent experiments. 
stronger antigen-specific CTL responses compared with the non-lipidated immunogen.

\section{rlipo-OVA elicits specific memory $\mathrm{CD8}^{+} \mathrm{T}$ cells}

Because the induction of long-lasting memory $\mathrm{CD}^{+}$ $\mathrm{T}$ cells is critical for successful cancer immunotherapy, we analyzed antigen-specific memory $\mathrm{CD}^{+} \mathrm{T}$ cells OT-I cells were adoptively transferred one day before immunization to evaluate whether the lipidated antigen could elicit specific memory CD8 T cell phenotypes. The lymphocytes from the popliteal and inguinal lymph nodes were pooled, and the splenocytes were isolated from the spleens of the immunized mice on day 28. Based on the expression of the CD44 and CD62L molecules on the OT-I

A

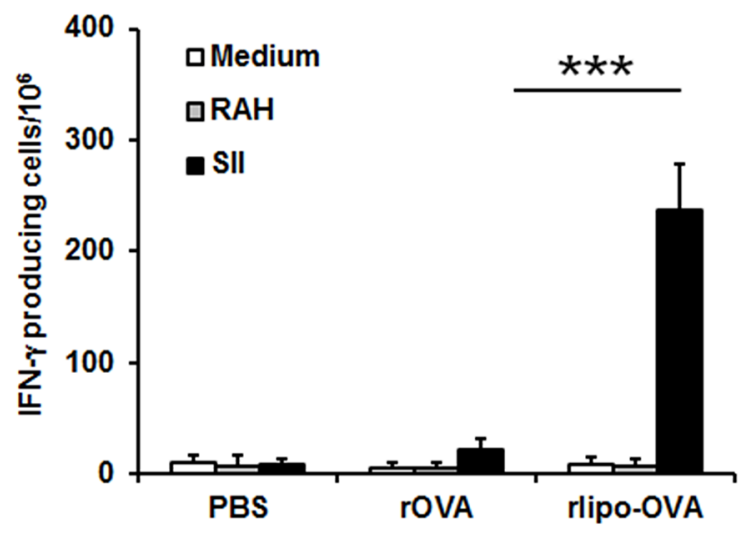

C

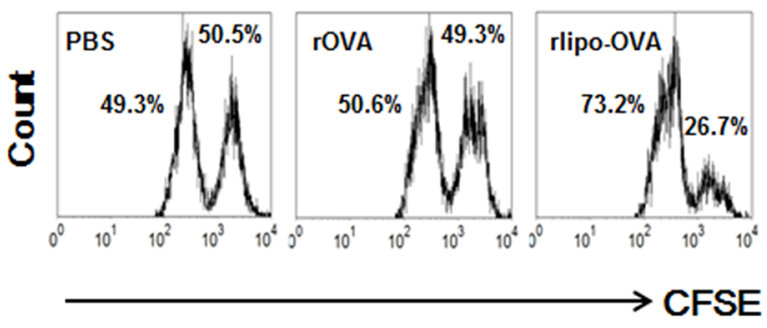

cells, the phenotypes of the $\mathrm{CD}^{+} \mathrm{T}_{\mathrm{CM}}$ and the $\mathrm{CD} 8^{+} \mathrm{T}_{\mathrm{EM}}$ populations were analyzed by flow cytometry (Figure 5A). There were no significant differences in the $\mathrm{T}_{\mathrm{CM}}$ cells $\left(\mathrm{CD} 44^{+} \mathrm{CD} 2 \mathrm{~L}^{+}\right)$populations among the PBS, rOVA, rlipo-OVA and Pam3+rOVA groups. In contrast, the $\mathrm{T}_{\mathrm{EM}}$ cells $\left(\mathrm{CD} 44^{+} \mathrm{CD} 62 \mathrm{~L}^{-}\right)$in the rlipo-OVA immunized mice were significantly higher compared with the PBS, rOVA or Pam3+rOVA groups in both the lymph nodes and spleens (Figure 5B). In addition to the traditional classification of the $\mathrm{T}_{\mathrm{CM}}$ and $\mathrm{T}_{\mathrm{EM}}$ populations, we measured the recall activity of memory $T$ cells using the CD27 and CD43 molecules. The expression of the CD27 and CD43 molecules was analyzed 28 days after immunization (Figure 5C). Surprisingly, the $\mathrm{CD} 27^{+} \mathrm{CD} 43^{+}$population was dramatically increased in the rlipo-OVA immunized

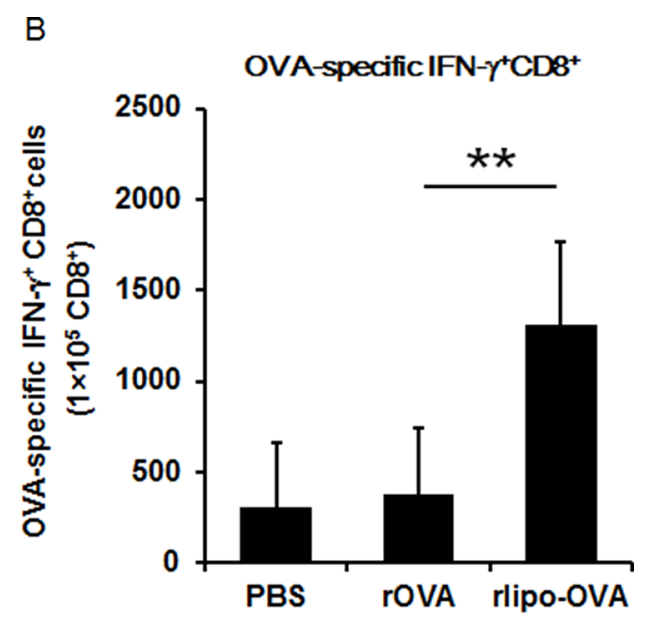

D

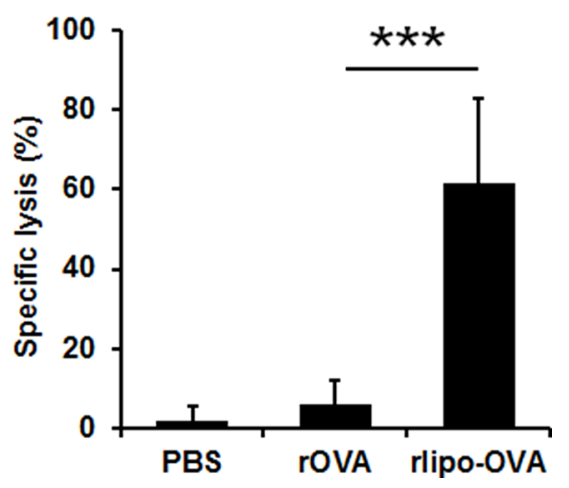

Figure 4: Immunization with rlipo-OVA induces higher levels of OVA-specific cytotoxic T cell responses compared to immunization with rOVA. C57BL/6 mice were immunized twice by subcutaneous injection at one-week intervals. The experiments were performed after seven days of last immunization. (A) A density of $5 \times 10^{5}$ splenocytes (per well) from immunized mice were incubated with $2.5 \mu \mathrm{g} / \mathrm{ml}$ of the irrelevant RAHYNIVTF (RAH) peptide or SII peptide for $48 \mathrm{~h}$ in an anti-IFN- $\gamma$-coated 96-well ELISPOT plate. The IFN- $\gamma$-secreting spots were calculated using an ELISPOT reader. The data are expressed as the mean + SD, $n=6 /$ per group. (B) The SIIspecific IFN- $\gamma$ production in $\mathrm{CD}^{+} \mathrm{T}$ cells. Splenocytes were isolated from each group of vaccinated mice. The cells were re-stimulated with $1 \mu \mathrm{g} / \mathrm{ml}$ of the SII peptides for $20 \mathrm{~h}$; for the final $4 \mathrm{~h}$, the cells were treated with $10 \mathrm{ng} / \mathrm{ml}$ phorbol 12-myristate 12 -acetate (PMA), $1 \mu \mathrm{g} / \mathrm{ml}$ ionomycin, and Brefeldin A solution. The percentages of $\mathrm{CD} 8^{+} / \mathrm{IFN}-\gamma^{+} \mathrm{T}$ cells pre-gated on $\mathrm{CD} 3^{+}$cells were determined by flow cytometry. The data are presented as the mean $+\mathrm{SD}, n=5$. (C) The graphs show the specific lysis of SII peptide-pulsed targets (CFSE ${ }^{\text {high }}$ ) and the un-pulsed peptide control (CFSElow). The graph summarizes the results of the specific lysis in vivo (D). The following equation was used to analyze specific lysis: $\%$ Specific lysis $=[(\%$ non-peptide $\times$ A $)-\%$ SII peptide $] /(\%$ non-peptide $\times$ A $)$. Adjustment factor A $=$ SII peptide/ non-peptide from the naïve controls. The data are expressed as the mean $+\mathrm{SD}$ of nine animals per group. 
mice but not in the PBS, rOVA or Pam3+rOVA groups in both the lymph nodes and spleens (Figure 5D). In contrast, there was no significant difference in the $\mathrm{CD} 27^{+} \mathrm{CD} 43^{-}$ memory $\mathrm{T}$ cell population among these groups. Apart the percentage of memory cells, the numbers of memory cells in the draining lymph nodes and spleens are calculated and shown (Figure S2). Additionally, we analyzed whether the memory $\mathrm{T}$ cells exhibited long-lived marker by monitoring the level of CD127 molecules in the $\mathrm{CD} 27^{+} \mathrm{CD} 43^{+}$ population. The $\mathrm{CD} 27^{+} \mathrm{CD} 43^{+}$cells expressed high levels of CD127 in the rlipo-OVA immunization (Figure 5E) and the representative cytometry histograms are shown (Figure S3). These results suggested that rlipo-OVA immunization was able to induce the long-lived effector $\mathrm{T}_{\mathrm{EM}}$ cells.

\section{Immunization with rlipo-OVA induces CD8- dependent anti-tumor effects and CD127 is functionally required for long term anti-tumor activity}

To evaluate whether the rlipo-OVA administration induces anti-tumor immunity, tumor-bearing mice were treated with PBS, rOVA and rlipo-OVA. C57BL/6 mice were subcutaneously injected with $2 \times 10^{4} \mathrm{EG} 7$ cells. Three days later, these mice received $30 \mu \mathrm{g}$ of rlipo-OVA, rOVA or PBS through subcutaneous injection in the dorsum. On day 28 post-tumor implantation, the tumor sizes of the surviving PBS and rOVA-treated mice were greater than $2.0 \mathrm{~cm}^{3}$. In contrast, the rlipo-OVA-treated mice were all alive, and their tumor sizes were $0.48 \pm 0.25 \mathrm{~cm}^{3}$ (Figure 6A). Similar results were obtained when the mice were immunized twice with PBS, rOVA and rlipoOVA and then subcutaneously injected with EG7 cells 7 days after the final immunization. On day 30 post-tumor challenge, the tumor sizes were barely measurable in the mice that received rlipo-OVA $\left(0.25 \pm 0.25 \mathrm{~cm}^{3}\right)$, whereas the tumor sizes in the rOVA-treated mice were greater than $2.0 \mathrm{~cm}^{3}$ (Figure S4). These results demonstrated that the lipidated immunogen could elicit robust anti-tumor immunity.

To investigate which T cell subset (including CD4 and CD8 cells) contributed to the anti-tumor immunity, we used anti-CD4 (rlipo-OVA/CD4), anti-CD8 (rlipoOVA/CD8) and control antibodies (rlipo-OVA/rat IgG) to deplete subsets of T cells. The mice were intraperitoneally injected with the antibody one day prior to challenge with EG7 cells. Three days later, the mice were received $30 \mu \mathrm{g}$ of rlipo-OVA. On day 23 after tumor inoculation, the average tumor sizes in the PBS and rlipo-OVA groups were $1.88 \pm 0.48 \mathrm{~cm}^{3}$ and $0.36 \pm 0.17 \mathrm{~cm}^{3}$, respectively. There were no significant differences in tumor sizes among the rlipo-OVA, rlipo-OVA/CD4 and rlipo-OVA/rat $\mathrm{IgG}$ groups. In contrast, the protective ability disappeared when the $\mathrm{CD}^{+}$cells were depleted in the rlipo-OVA/CD8 group ( $p<0.001$, vs. rlipo-OVA; Figure 6B). These data showed that $\mathrm{CD}^{+} \mathrm{T}$ cells played a major role in antitumor immunity following immunization with rlipo-OVA.

To evaluate whether the induction of memory $\mathrm{T}$ cells was important for anti-tumor immunity, the mice were subcutaneously immunized at the base of the tail on days 0 and 7 . After 28 days immunization, the splenocytes were harvested to measure the number of OVA-specific IFN- $\gamma$-secreting cells using the ELISPOT assay. The results showed that immunization with rlipo-OVA induced higher numbers of SII-specific INF- $\gamma$-secreting cells (122.0 $\pm 12.0)$ compared with rOVA $(70.7 \pm 8.6$; rOVA vs. rlipoOVA, $p<0.001$; Figure $6 \mathrm{C}$ ). The tumor challenge results were obtained when the mice were immunized twice with immuogens and then subcutaneously injected with EG7 cells 28 days after the final immunization. On day 28 post-tumor challenge, the tumor sizes were measured in the mice that received rlipo-OVA $\left(0.53 \pm 0.30 \mathrm{~cm}^{3}\right)$, and the tumor sizes in the PBS- or rOVA-treated mice were greater than $2.0 \mathrm{~cm}^{3}$ (Figure 6D). These data showed that rlipo-OVA induced long term anti-tumor activity.

To clarify the role of the long-lived effector memory $\mathrm{T}$ cells, we used an anti-CD127 antibody to deplete $\mathrm{CD} 127^{+}$cells. Ten days after the last immunization, the mice were intraperitoneally injected with anti-CD127 or the control antibody (rat $\mathrm{IgG}$ ); then, the mice were challenged with EG7 cells on day 35. There were no significant differences between the rlipo-OVA- and rlipo$\mathrm{OVA} / \mathrm{rat}$ IgG-treated mice. Interestingly, the protective ability was abolished when the CD127 cells were depleted in the rlipo-OVA/CD127 group ( $p<0.05$, vs. rlipo-OVA, Figure $6 \mathrm{E}$ ). These data indicated that $\mathrm{CD} 127^{+} \mathrm{T}$ cells were critical for recombinant lipoimmunogen-induced antitumor immunity.

\section{DISCUSSION}

Previous studies have explored the important role of memory $\mathrm{CD}^{+} \mathrm{T}$ cell differentiation in the rational design of vaccines against virus-infected or cancer cells. Currently, novel vaccine adjuvants are designed to target innate receptors (i.e., TLRs) and to enhance long-lived memory $\mathrm{CD}^{+} \mathrm{T}$ cell differentiation. In this report, we investigated whether a TLR2 ligand-fused antigen could increase antigen presentation and generate long-lived memory $\mathrm{CD}^{+} \mathrm{T}$ cells. Our data showed that rlipo-OVA could not only activate BM-DC maturation but also efficiently present the SII peptide on MHC I molecules via TLR2 (Figures 2 and 3). After immunization, rlipo-OVA induced higher levels of OVA-specific antibody responses than rOVA (Figure S5A). Consistent with our previous report [33], immunization with rlipo-OVA skewed the immune response towards a Th1-biased immune responses (Figure S5B-S5D). Moreover, rlipo-OVA induced a strong OVA-specific CTL response (Figure 4). The induction of the OVA-specific CTL function capable of inhibiting tumor growth persisted for at least four weeks 


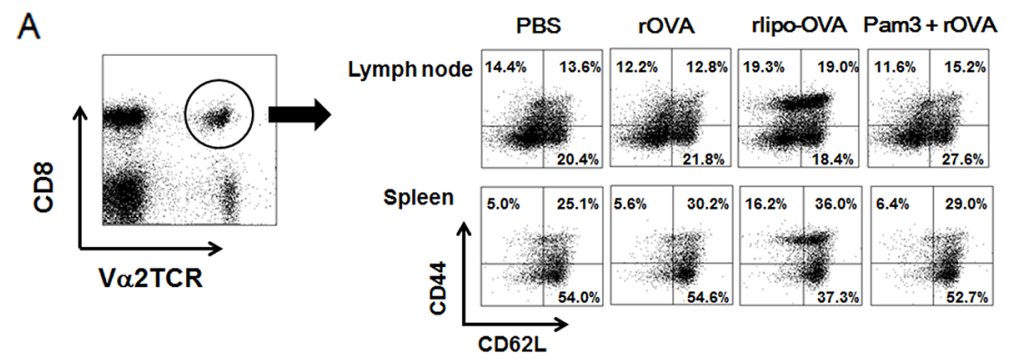

B

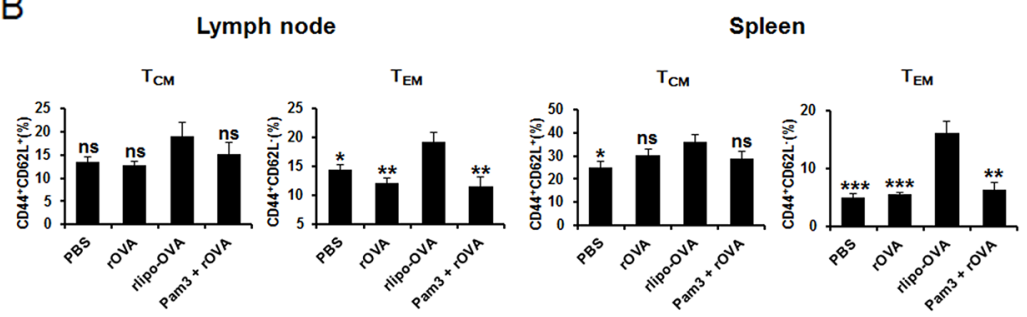

C

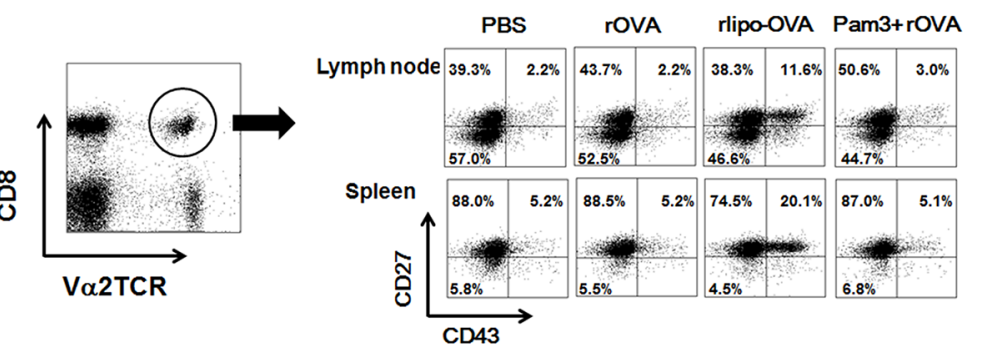

D

Lymph node

Spleen

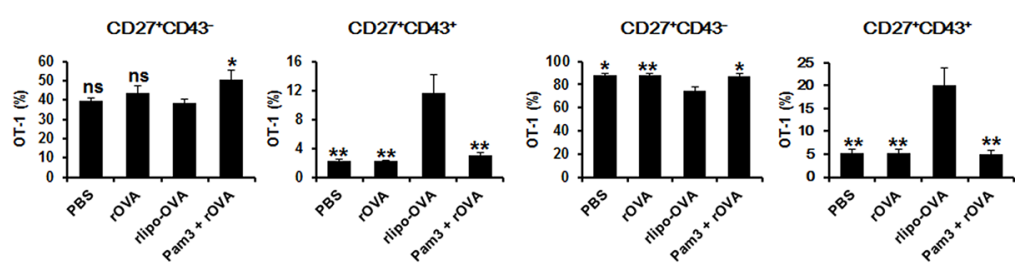

E

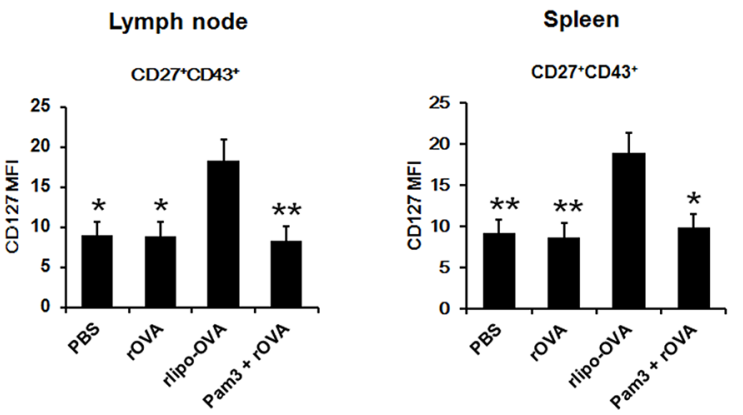

Figure 5: Immunization with rlipo-OVA increases memory CD8 $\mathbf{T}$ cells. $5 \times 10^{5}$ OT-I CD8 ${ }^{+} \mathrm{T}$ cells were adoptively transferred via the tail vein one day before once immunization. The mice were injected in each footpad with either PBS alone, rlipoOVA $(5 \mu \mathrm{g})$, rOVA $(5 \mu \mathrm{g})$, or rOVA $(5 \mu \mathrm{g})$ formulated with an equal molar amount of Pam3CSK 4 in $50 \mathrm{ml}$ of PBS. For the analysis of memory populations, the lymphocytes were pooled from the popliteal and inguinal lymph nodes and splenocytes were isolated from the spleens from the groups of immunized mice 28 days after once immunization. The cells were stained with Va2TCR-PE and CD8a-APC. (A) The antibodies CD44-FITC and CD62L-APC were used to evaluate $\mathrm{T}_{\mathrm{CM}}$ cells $\left(\mathrm{CD} 44^{+} \mathrm{CD}_{62} \mathrm{~L}^{+}\right)$and $\mathrm{T}_{\mathrm{EM}}$ cells $\left(\mathrm{CD} 44^{+} \mathrm{CD} 62 \mathrm{~L}^{-}\right)(\mathbf{B})$. (C) The antibodies CD27-FITC and CD43 PE-Cy7 were used to assess effector CD8 ${ }^{+} \mathrm{T}$ cells in the memory population evaluated for the expression of $\mathrm{CD} 27^{+} \mathrm{CD} 43^{-}$and $\mathrm{CD} 27^{+} \mathrm{CD} 43^{+}$(D). The $\mathrm{CD} 127$ marker was used to evaluate the $\mathrm{CD} 27^{+} \mathrm{CD} 43^{+}$memory population in the lymph nodes and spleens $(\mathbf{E})$. The data are expressed as the mean + SEM. ns $=$ not significant, ${ }^{*} p<0.05, * * p<0.01$ and $* * * p<0.001$ are significant differences compared to rlipo-OVA, $n=6$. 
A
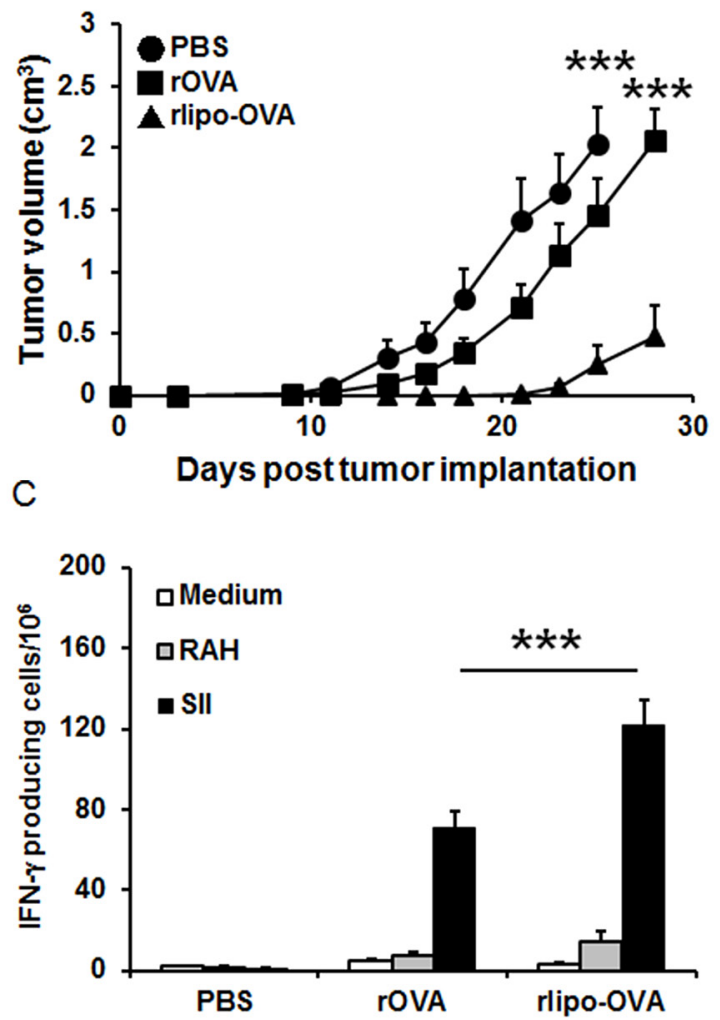

E

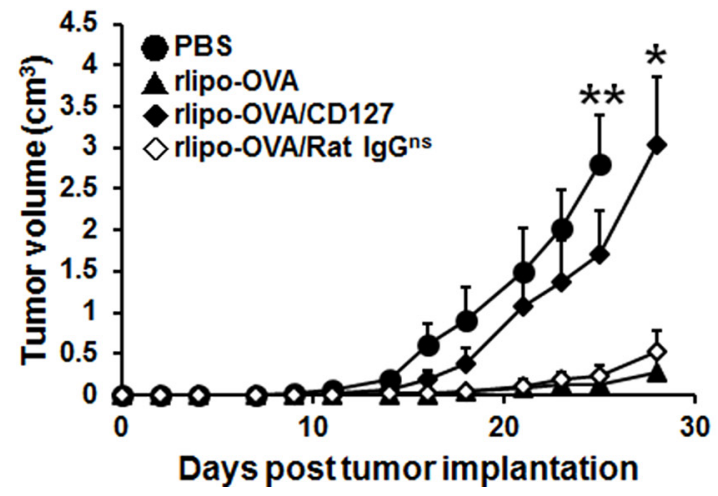

$\mathrm{B}$
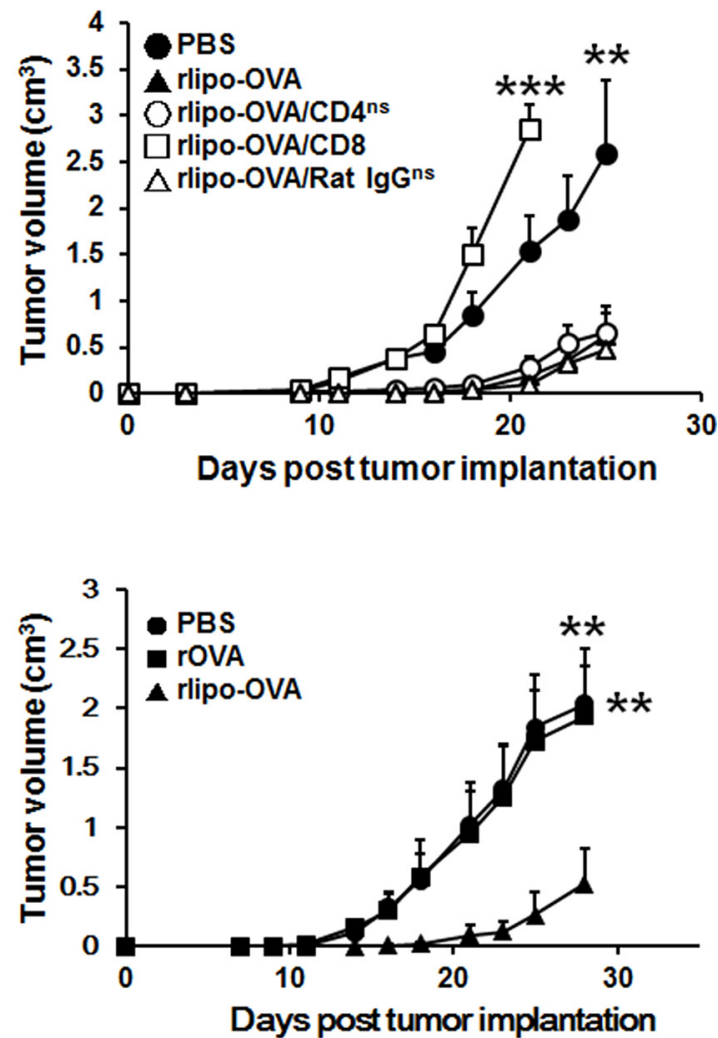

Figure 6: Immunization with rlipo-OVA induces CD8-dependent anti-tumor effects and the functional requirement of CD127 for long term anti-tumor ability. (A) The mice were inoculated with $2 \times 10^{4}$ EG7 cells in a total volume of $200 \mu 1$ of PBS. After 3 days, tumor-bearing mice were subcutaneously injected once with rOVA $(30 \mu \mathrm{g})$, rlipo-OVA ( $30 \mu \mathrm{g})$ or PBS $(n=12)$. (B) Three groups (rlipo-OVA/CD4, rlipo-OVA/CD8 and rlipo-OVA/Rat IgG) of mice were injected with anti-CD4, anti-CD8 and control antibodies one day before the injection of rlipo-OVA ( $30 \mu \mathrm{g} /$ mouse). On day 3 , these groups and two additional control groups (rlipo-OVA and PBS) were subcutaneously injected once with rlipo-OVA (30 $\mu \mathrm{g} /$ mouse) or PBS at the base of tail after inoculation with EG7 cells $\left(2 \times 10^{4} /\right.$ per mouse; $n=6$ ). (C and $\mathbf{D})$ Mice were immunized twice by subcutaneous injection of rOVA $(30 \mu \mathrm{g})$, rlipo-OVA $(30 \mu \mathrm{g})$ or PBS alone at oneweek intervals, and the experiments were performed 4 weeks after the final immunization. (C) The splenocytes $\left(5 \times 10^{5}\right.$ cells/well) from the groups of immunized mice were incubated with or without $5 \mu \mathrm{g} / \mathrm{ml}$ of the RAH peptide or SII peptide for $48 \mathrm{~h}$ in an anti-IFN- $\gamma$-coated 96-well ELISPOT plate. The IFN- $\gamma$-secreting spots were measured using an ELISPOT reader $(n=6)$. (D) The mice were subcutaneously injected with a density of $2 \times 10^{4} \mathrm{EG} 7$ cells in a total volume of $200 \mu$ l. Tumor growth was observed three times per week $(n=8)$. (E) Three groups of C57BL/6 mice were subcutaneously injected with rlipo-OVA $(30 \mu \mathrm{g})$, and the control group was administered PBS at one-week intervals. On day 17, two groups of immunized rlipo-OVA mice were treated intraperitoneally (i.p.) with either $0.5 \mathrm{mg}$ of rat anti-mouse CD127 antibody or $0.5 \mathrm{mg}$ of rat anti-mouse IgG antibody. A total of $2 \times 10^{4} \mathrm{EG} 7$ tumor cells were inoculated on day 35 . The data are shown as the means $+\mathrm{SE},(n=6)$. The tumor volume was calculated as the length $\times$ width $\times$ width $\times 1 / 2\left(\mathrm{~mm}^{3}\right)$. The data are shown as the mean $+\mathrm{SEM}, \mathrm{ns}=$ no significant difference, ${ }^{*} p<0.05,{ }^{* *} p<0.01$ and ${ }^{* * *} p<0.001$ indicate significant differences compared with rlipo-OVA. 
(Figure 6C and 6D) and the secondary challenge after 80 days immunization also had protection of anti-tumor (Figure S6). Importantly, we found that immunization with rlipo-OVA increased the differentiation of $\mathrm{CD} 44^{+} \mathrm{CD} 62 \mathrm{~L}^{-}$ and $\mathrm{CD} 27^{+} \mathrm{CD} 43^{+} \mathrm{T}_{\mathrm{EM}}$ cells; the latter cells expressed high levels of the long-lived CD127 marker. CD127 is also a memory marker, and high expression of the CD127 marker preferentially causes memory cells to persevere and confer immunity for protection [34]. The depletion of $\mathrm{CD} 127^{+}$ cells led to the loss of the anti-tumor function induced by rlipo-OVA (Figure 6E). These findings suggested that the TLR2 agonist-fused antigen was able to induce long-lived memory $\mathrm{CD} 8^{+} \mathrm{T}$ cells for efficient cancer therapy.

The advantage of the use of a TLR ligand-fused antigen for the induction of CTL responses is the efficient co-localization of the TLR ligands and antigen in the same APCs. Our previous study showed that a TLR2 ligandconjugated long peptide could regulate the presentation of antigen [15]. Here, we confirmed that peptide/MHC class I complexes were detected on the surface of APCs using OVA as a model antigen (Figure 3 ). In addition to the TLR2 ligands, the TLR7 agonist conjugated with antigen also enhanced more efficient cross-presentation in DCs and $\mathrm{CD}^{+} \mathrm{T}$ cell responses than its unconjugated counterpart [14]. Compared with the free adjuvant, coupling TLR9 ligands to nanoparticles could induce cross-presenting dendritic cells and greatly enhance the adjuvant efficacy at low doses, thereby driving stronger effector $\mathrm{CD} 8^{+}$ T-cell activation by enhancing their cytolytic profiles and inducing more powerful memory $\mathrm{T}$ cells [35]. These data suggested that TLR ligands conjugated to antigen could be efficiently processed and presented to $\mathrm{CD} 8^{+} \mathrm{T}$ cells.

Several TLR ligands can induce memory $\mathrm{T}$ cells. Mice vaccinated with a TLR2 agonist-based lipopeptide could induce memory $\mathrm{T}$ cells, recall specific $\mathrm{T}$ cells, and mediate the reduction of pulmonary viral titers following challenge with virus [36]. The long-lived effector CD8 ${ }^{+}$ memory $\mathrm{T}$ cells in the memory population are optimal for potent protective immunity due to their longevity and their ability to rapidly expand their numbers and induce protective cytokine and cytotoxic molecules against certain pathogens [34, 37]. TLR4 ligand-elicited memory $\mathrm{CD} 8^{+} \mathrm{T}$ cell differentiation is dependent on MyD88 signals [38]. Interestingly, TLR3 and TLR9 ligands can induce efficient CTL responses and fully functional memory $\mathrm{CD}^{+} \mathrm{T}$ cells without $\mathrm{CD} 4^{+} \mathrm{T}$ cell help $[39,40]$. Papaya mosaic virus nanoparticles (PapMV) enhanced effector and memory $\mathrm{CD}^{+} \mathrm{T}$ cell responses via TLR7 to increase protection against a Listeria monocytogenes challenge [41]. Our results showed that once immunization of TLR2 ligand-fused antigen could increase the numbers of $\mathrm{CD} 27^{+} \mathrm{CD} 127^{+}$memory $\mathrm{T}$ cells (Figure S7). The elimination of $\mathrm{CD} 127^{+}$cells failed to induce anti-tumor immunity (Figure 6E). Although CD 27 population is reduced about $60 \%$ after prime-boost to compare immune once [42] and the prime-boost regimens are often used to elicit large numbers of memory CD8 ${ }^{+} \mathrm{T}$ cells $[43,44]$, but the protection of memory $\mathrm{T}$ cell is not decreased by encouraging CD27 negative populations after primeboost regimens [37]. Moreover, when the immunogen re-challenged, the generated population of $\mathrm{CD} 27^{+} \mathrm{CD} 43^{-}$ and $\mathrm{CD} 27^{+} \mathrm{CD} 43^{+}$have ability to immediately recall killing responses [24]. Here, in Figure 6C-6D and Figure S6, after 28 days prime-boost regimens, the rlipo-OVA could induce anti-tumor ability and also in secondary tumor challenge on day 80 . Unexpectedly, we did not observe an increase in $\mathrm{T}_{\mathrm{CM}}$ cells after rlipo-OVA immunization. This result suggests that $\mathrm{T}_{\mathrm{CM}}$ differentiation may require a second immunization. The expansion of $T_{C M}$ cells is very rapid after heterologous prime-boosting [45] or viral challenge [46]. Although we did not elucidate the mechanism by which TLR 2 regulated the differentiation of $\mathrm{T}_{\mathrm{EM}}$ or $\mathrm{T}_{\mathrm{CM}}$ cells, we believe that the induction of cytokine profiles and transcriptomic regulation may contribute to the differentiation of memory T cells (i.e., TLR4 signaling) [38]. However, different TLRs may have different gene expression signatures that may lead to different effects on the differentiation of $\mathrm{T}_{E M}$ or $\mathrm{T}_{C M}$ cells after vaccination.

Formulating immunogen with proper adjuvants is the most important consideration in developing effective vaccines and conquering the limitations of protein-based immunotherapies. To elicit strong CTLs against cancer cells, the manipulation of the immune response bias to Th1 is critical. Shirota and coworkers [47] reported that the covalent linkage of the antigen with the adjuvant was 100 -fold more effective than the unconjugated mixture for Th1 differentiation in vitro. In our study, we found that rlipo-OVA induced higher numbers of SII-specific INF- $\gamma$-secreting cells than rOVA mixed with the $\mathrm{N}$-terminal segment of recombinant lipoimmunogen (rlipo-Nter; Figure S8). Previous studies have demonstrated the effective adjuvant activities of synthetic lipopeptides, lipoprotein produced from bacteria and lipidtailed glyco-peptides [48-50]. These results suggested that co-delivery of TLR ligands and antigens could be a promising approach for the development of novel vaccines.

In conclusion, the recombinant lipoimmunogen technology can easily be applied to other tumor-associated antigens with limited constraints. This strategy provides a new direction for the development of successful immunotherapies using protein-based candidates and will hopefully yield safe and effective vaccines for human use.

\section{MATERIALS AND METHODS}

\section{Chemicals}

All experimental chemicals were purchased from Sigma-Aldrich (St. Louis, MO, USA) and Merck (Darmstadt, Germany). Restriction enzymes and the ligase for plasmid construction were purchased from New 
England Biolabs, Inc. (Beverly, MA, USA). The primers used for cloning were purchased from Mission Biotech, Inc. (Taipei, Taiwan). Trypsin and the matrix for mass spectrometry analysis were purchased from Promega Co. (Madison, WI, USA). Ovalbumin (OVA) grade V (SigmaAldrich) used as a control after LPS removal (less than $0.01 \mathrm{EU} / \mu \mathrm{g})$.

\section{Cloning and expression of recombinant proteins}

The OVA gene of Gallus gallus (accession number: P0102) was amplified by conventional PCR. To generate an expression plasmid for rOVA, the following primers were used: forward primer, 5'-GGAATTCCATATGGGCAGCATTGGCGCGGCGAG CAT-3' (Nde I site underlined) and reverse primer, 5'-CCGCTCGAGCGGGCTCACGCAACGGGCCAAAA AAC-3' (Xho I site underlined). The PCR product was cloned into the expression vector pET-22b(+) (Novagen, Madison, WI, USA) using the Nde I and Xho I sites to produce the pOVA plasmid. As a result, rOVA contained an additional hexahistidine tag (HisTag) at its C-terminus. The E. coli strain BL21 (DE3) (Invitrogen, Carlsbad, CA, USA) was transformed with the expression plasmid pOVA for rOVA expression. The transformed cells were cultured at $20^{\circ} \mathrm{C}$ overnight in LB broth and then scaled up to $37^{\circ} \mathrm{C}$ until an OD of $0.6-1.0$ was reached. rOVA expression was induced by adding $1 \mathrm{mM}$ IPTG at $12^{\circ} \mathrm{C}$ for 3 days, and the cells were harvested by centrifugation.

Next, we generated the expression plasmid for the recombinant rlipo-OVA. In our previous report [29], pD1E3 was used to generate an rlipoOVA (pLOVA) expression plasmid. The primers used for this step were as follows: forward primer, 5'-CGGGATCCATGGGCAGCATTGGCGCGGCGAG CAT-3' (Bam HI site underlined) and reverse primer, 5'-CCGCTCGAGCGGGCTCACGCAACGGCCAAAA AAC-3' (Xho I site underlined). The PCR product of the OVA gene was cloned into pD1E3 using the Bam HI and Xho I sites to produce the pLOVA plasmid. As a result, the C-terminus of rlipo-OVA contained an additional hexahistidine tag (HisTag). The E. coli strain C43(DE3) (Invitrogen) was transformed with the expression plasmid pLOVA for rlipo-OVA expression. The transformed cells were cultured at $20^{\circ} \mathrm{C}$ overnight in LB broth and then amplified at $37^{\circ} \mathrm{C}$ until an OD of $0.6-1.0$ was reached. Protein expression was induced by adding $1 \mathrm{mM}$ IPTG at $12^{\circ} \mathrm{C}$ for 3 days, and the cells were harvested by centrifugation.

\section{Purification of recombinant proteins}

rOVA was expressed in the E. coli BL21(DE3) strain. After the cells were disrupted in a French Press (Constant Systems, Daventry, UK) at $27 \mathrm{Kpsi}$ in homogenization buffer [20 mM Tris (pH 8.0), $50 \mathrm{mM}$ sucrose, $500 \mathrm{mM}$ $\mathrm{NaCl}$ and $10 \%$ glycerol], the cell lysate of rOVA was clarified by centrifugation (32,000 rpm for $40 \mathrm{~min})$. The supernatant was loaded onto a column (BIO-RAD, Hercules, CA, USA, $2.5 \mathrm{~cm}$ i.d. $\times 10.0 \mathrm{~cm})$ containing $20 \mathrm{ml}$ Ni-NTA resin (Qiagen, San Diego, CA, USA) and washed with the extraction buffer and then the same buffer containing $20 \mathrm{mM}$ imidazole. Then, rOVA was eluted with the homogenization buffer containing $300 \mathrm{mM}$ imidazole. The eluted rOVA was dialyzed to $20 \mathrm{mM}$ Tris $(\mathrm{pH} \mathrm{8.0)}$ three times for at least $6 \mathrm{~h}$ each time. After dialysis, the rOVA was loaded onto a 20-ml Q Sepharose fast flow column (GE Healthcare, Little Chalfont, Buckinghamshire, UK) and washed with dialysis buffer. The rOVA was eluted with dialysis buffer containing $150 \mathrm{mM} \mathrm{NaCl}$. Mustang E membrane (Pall corporation, NY, USA) was used to remove lipopolysaccharide (LPS) and to exchange the buffer with phosphate buffer saline (PBS). The amount of residual LPS in the rOVA preparations was analyzed using the Limulus amebocyte lysate (LAL) assay (Associates of Cape Cod Inc., East Falmouth, MA, USA). The LPS levels were reduced to less than $5 \mathrm{EU} / \mathrm{mg}$.

To purify rlipo-OVA, the harvested cells were disrupted in a French Press at 27 Kpsi in homogenization buffer. The pellet of the cell lysate was collected by centrifugation $(32,000 \mathrm{rpm}$ for $40 \mathrm{~min})$. rlipo-OVA was extracted from the pellet using solubilization buffer $[1 \%$ Triton X-100 and $20 \mathrm{mM}$ Tris ( $\mathrm{pH} \mathrm{8.0)].} \mathrm{The} \mathrm{extraction}$ supernatant was collected by centrifugation. The supernatant was incubated with $25 \mathrm{ml}$ of Ni-NTA resin (Qiagen) overnight and loaded into a column. The column was washed with the washing buffer $[0.1 \%$ Triton X-100, $0.3 \mathrm{M} \mathrm{NaCl}$ and $20 \mathrm{mM}$ Tris (pH 8.0)] followed by the same buffer containing $30 \mathrm{mM}$ imidazole, and then washed with a 100-fold column volume of $20 \mathrm{mM}$ Tris ( $\mathrm{pH} 7.4$ ) containing $0.1 \%$ Triton X-114 to remove the LPS. Next, the column was washed with $20 \mathrm{mM}$ Tris $(\mathrm{pH} 7.4)$ to remove the residual detergent, and rlipo-OVA was eluted with 20 $\mathrm{mM}$ Tris ( $\mathrm{pH}$ 7.4) containing $300 \mathrm{mM}$ imidazole. The solubilization buffer was exchanged with PBS. Endotoxin levels were found to be below $0.01 \mathrm{EU} / \mu \mathrm{g}$.

\section{Analysis of purified recombinant proteins}

The purified rOVA and rlipo-OVA were analyzed by SDS-PAGE, immunoblotting, protein identification and N-terminal amino acid sequencing. The proteins were transferred to a PVDF membrane after separation by SDS-PAGE. The blot was stained with Coomassie Blue R-250. The stained PVDF membrane was washed with de-stain buffer (50\% methanol) until bands appeared. The protein bands were excised from the blot. The excised rOVA and rlipo-OVA bands were subjected to four cycles of Edman degradation using an Applied Biosystems Model 494 Protein Sequencer (Mission Biotech). For protein identification, the protein was digested with trypsin for three days at $37^{\circ} \mathrm{C}$. The $\mathrm{N}$-terminal fragments in the reaction mixture was further purified using Ziptip 
(Millipore, MA, USA) after trypsin digestion. The mixture or purified tryptic fragments were mixed with a saturated solution of $\alpha$-ciano-4-hydroxycinnamic acid in acetonitrile $/ 0.1 \%$ trifluoroacetic acid $(1: 3, \mathrm{vol} / \mathrm{vol})$. The mixture was placed on the target plate of a MALDI-TOF instrument (Waters, Milford, MA, USA) for analysis.

\section{Splenocyte proliferation assay}

Splenocytes from C57BL/6 mice were plated at a density of $2.5 \times 10^{5} /$ well in 96-well plates and stimulated with LPS $(10,100$, and $1000 \mathrm{ng} / \mathrm{ml})$ or the indicated concentrations of OVA, rOVA, rlipo-OVA or Pam3CSK4 for a total of $72 \mathrm{~h}$ at $37^{\circ} \mathrm{C}$ in a $5 \% \mathrm{CO}_{2}$ humidified incubator. After $72 \mathrm{~h}, 10 \%$ CellTiter $96^{\circledR} \mathrm{AQ}_{\text {ueous }}$ One Solution Reagent (Promega) was added to each well to measure cell proliferation. The absorbance was measured with an ELISA reader at $490 \mathrm{~nm}$. All results are presented as the mean absorbance $\mathrm{OD} \pm$ standard deviation (SD).

\section{Activation of BM-DCs}

BM-DCs derived from WT, TLR2KO and MyD88KO mice were cultured and assessed as previously described [29]. Briefly, mouse bone marrow cells were cultured at a density of $2 \times 10^{6}$ cells in Petri dishes containing $10 \mathrm{ml}$ of complete RPMI-1640 supplemented with $200 \mathrm{unit} / \mathrm{ml}(20 \mathrm{ng} / \mathrm{ml})$ recombinant mouse GM-CSF (PeproTech, Rocky Hill, NJ, USA). An additional $10 \mathrm{ml}$ of complete RPMI containing $20 \mathrm{ng} / \mathrm{ml}$ GM-CSF was added on day 3 . The cells were collected from each dish and counted on day 6 . BM-DCs $\left(1 \times 10^{6}\right.$ cells $\left./ \mathrm{ml}\right)$ were stimulated with the indicated concentrations of rOVA, rlipo-OVA, LPS, Pam3CSK4 or medium for 18 h. Cell surface markers [CD11c (clone HL3, BD Biosciences, San Jose, CA, USA), CD40 (clone 3/23, BD Biosciences) and CD80 (clone B7-1, eBioscience, San Diego, CA, USA)] of BM-DCs were analyzed using the FACSCalibur (BD Biosciences). The production of cytokines by BM-DCs (TNF- $\alpha$ and IL-12p40) was determined using ELISA kits (eBioscience).

\section{Antigen presentation}

To investigate OVA-H- $2 \mathrm{~K}^{\mathrm{b}}$ production, BM-DCs were incubated for $24 \mathrm{~h}$ with PBS, OVA, or rlipo-OVA and stained with CD16/CD32 (clone 2.4G2, BD Biosciences) prior to cell surface staining with the CD11c-FITC (clone N418, Biolegend, San Diego, CA, USA) and SII/H-2K (clone 25-D1.16, eBioscience) antibodies and the isotype control antibody (mouse IgG1 $\kappa$, BD Biosciences). Then, the cells were subjected to intracellular $\mathrm{SII} / \mathrm{H}-2 \mathrm{~K}^{\mathrm{b}}$ or isotype control antibody staining using the Intracellular Fixation \& Permeabilization Buffer Set according to the manufacturer's instructions (eBioscience). To confirm the presentation of $\mathrm{SII} / \mathrm{H}-2 \mathrm{~K}^{\mathrm{b}}$ could activate $\mathrm{T}$ cells, BM-DCs $\left(1 \times 10^{4}\right)$ were cultured with $1 \times 10^{5}$ OT-I cells (purity $>$ $90 \%$ ) which were purified by $\mathrm{CD} 8 \mathrm{a}^{+} \mathrm{T}$ cell isolation kit (Miltenyi Biotec, Auburn, CA, USA), $1 \mu \mathrm{Ci} /$ well $\left[{ }^{3} \mathrm{H}\right]$ thymidine (Perkin-Elmer Life Science, Boston, MA) was added at $54 \mathrm{~h},\left[{ }^{3} \mathrm{H}\right]$ thymidine incorporation was measured at $72 \mathrm{~h}$ of culture, and performing scintillation counting. The level of IFN- $\gamma$ was determined using ELISA kits (eBioscience) on day 5.

\section{ELISPOT assay}

IFN- $\gamma$-secreting cells were calculated using an IFN- $\gamma$ ELISPOT assay (eBioscience) as previously described [32]. Briefly, splenocytes $\left(5 \times 10^{5} /\right.$ well $)$ were added to anti-IFN- $\gamma$-coated ELISPOT plates (Millipore) and cultured in medium alone or in the presence of $2.5 \mu \mathrm{g} /$ $\mathrm{ml}$ of the indicated peptides in a final volume of $200 \mu \mathrm{l}$ of complete RPMI-10. After two days of incubation, the cells were removed by washing the plates with PBST $[0.05 \%$ (w/v) Tween 20 in PBS]. Then, $10 \mu \mathrm{g} / \mathrm{ml}$ of biotinylated anti-IFN- $\gamma$ antibody was added to each well in $100-\mu 1$ aliquots, and the samples were incubated for $2 \mathrm{~h}$. The spots were developed using 3-amine-9-ethyl carbazole (Sigma-Aldrich) and counted by an ELISPOT reader (Cellular Technology Ltd., Shaker Heights, OH, USA).

\section{Intracellular cytokine staining and flow cytometry analysis}

C57BL/6 mice were immunized twice by a subcutaneous injection of rOVA $(30 \mu \mathrm{g})$, rlipo-OVA $(30 \mu \mathrm{g})$ or PBS at one-week intervals. Seven days after the final immunization, splenocyte $\mathrm{CD}^{+} \mathrm{T}$ cells producing IFN- $\gamma$ were determined by intracellular cytokine flow cytometry. The peptides used to stimulate the cells were added at a concentration of $2 \mu \mathrm{g} / \mathrm{ml}$ for $18 \mathrm{~h}$ at $37^{\circ} \mathrm{C}$; then, $1 \mu \mathrm{l} /$ $\mathrm{ml}$ of Brefeldin A (eBioscience), $1 \mu \mathrm{g} / \mathrm{ml}$ ionomycin (Sigma-Aldrich) and $10 \mu \mathrm{g} / \mathrm{ml}$ phorbol 12-myristate 12-acetate (PMA) were added for an additional $4 \mathrm{~h}$ before harvesting the cells from the culture. The cells were subjected to intracellular cytokine (IFN- $\gamma$ ) staining using the Intracellular Fixation \& Permeabilization Buffer Set (eBioscience) according to the manufacturer's instructions. The cells were washed once with FACS buffer (PBS, 2\% FBS and $0.05 \%$ sodium azide) and stained with the following monoclonal antibodies: CD16/CD32 (clone 93, eBioscience), CD3 $\varepsilon$-PE (clone 145-2c11, Biolegend), CD8a-APC (clone 53-6.7, eBioscience), IFN- $\gamma$-PE-Cy7 (clone XMG1.2, eBioscience) and the isotype control antibody (rat IgG1k, eBioscience). Sample acquisition was analyzed using the FACSCalibur (BD Biosciences).

\section{In vivo cytolysis assay}

Cytolysis was analyzed using a flow cytometry assay as previously described [51]. Briefly, C57BL/6 
mice were immunized twice by subcutaneous injection of rOVA $(30 \mu \mathrm{g})$, rlipo-OVA $(30 \mu \mathrm{g})$ or PBS at oneweek intervals. Seven days after the final immunization, the splenocytes were washed in PBS. The cells alone (no peptide) and the SII peptide-pulsed cells were labeled at final concentrations of $1 \mu \mathrm{M}$ CFSE (Molecular Probes, Eugene, OR, USA) and $10 \mu \mathrm{M}$ CFSE, respectively. The CFSE-labeled cells $\left(2 \times 10^{7}\right.$ cells/mouse $)$ were adoptively transferred via tail vein injection into the immunized mice. The experimental cells from the splenocytes were harvested $18 \mathrm{~h}$ after adoptive transfer and analyzed using FACSCalibur. The adjustment factor (A) was calculated by dividing the percentage of cells loaded without peptide by the percentage of cells loaded with SII peptide in the naïve controls. The specific lysis percentage was calculated using the equation: $\%$ Specific lysis $=[(\%$ non-peptide $\times$ A) $-\%$ SII peptide] / $(\%$ non-peptide $\times$ A $)$.

\section{Phenotype of memory $\mathrm{CD8}^{+} \mathrm{T}$ cells}

C57BL/ 6 mice received $5 \times 10^{5}$ OT-I $\mathrm{CD}^{+} \mathrm{T}$ cells 1 day before inoculation in the footpad with PBS, $5 \mu \mathrm{g}$ of rlipo-OVA, $5 \mu \mathrm{g}$ of rOVA, and $5 \mu \mathrm{g}$ of rOVA formulated with equal molar Pam3CSK4. To evaluate whether the lipidated antigen elicited specific memory CD8 T cell phenotypes, the lymphocytes were pooled from the popliteal, and inguinal lymph nodes and splenocytes were isolated from the spleens from the immunized mice 28 days after immunization. The Fc receptors were blocked with CD16/CD32 (clone 93, eBioscience), and the cells were stained with anti-CD27-FITC (clone LG.7F9, eBioscience), anti-CD44-FITC (clone IM7, BD Bioscience), anti-Va2TCR-PE (clone B20.1, BD Bioscience), anti-CD43 PE-Cy7 (clone 1B1.1, Biolegend), anti-CD127 PerCP-Cy5.5 (clone A71234, eBioscience), anti-CD62L-APC (clone MEL-14, BD Bioscience) and anti-CD8a-APC/Cy7 (clone 53-6.7, BD Bioscience). The acquisitions were determined using the LSRII flow cytometer (BD Bioscience).

\section{Cell lines and animal studies}

EG7 is a mouse leukemia cell line transformed with the ovalbumin plasmid. EG7 cells were cultured in RPMI 1640 (HyClone, Logan, UT, USA) supplemented with $20 \mathrm{mM}$ HEPES (HyClone), 10\% heat-inactivated fetal bovine serum (HyClone), penicillin (100 units/ml), streptomycin $(100 \mu \mathrm{g} / \mathrm{ml}), 1 \mathrm{mM}$ sodium pyruvate, $50 \mu \mathrm{M}$ $\beta$-mercaptoethanol and $0.4 \mathrm{mg} / \mathrm{ml} \mathrm{G} 418$ at $37^{\circ} \mathrm{C}$ under $5 \% \mathrm{CO}_{2}$.

Six- to twelve-week-old female C57BL/6 mice were purchased from the National Laboratory Animal Breeding and Research Center (Taipei, Taiwan). All animals were maintained in accordance with the institutional animal care protocol and housed at the Animal Center of National Health Research Institutes (NHRI, Taiwan). All animal studies were approved by the animal committee of the NHRI for this study (approval ID: NHRI-IACUC101039-A). In the therapeutic model, the mice were first injected with $2 \times 10^{4}$ EG7 tumor cells in the left flank. On the third day after the tumor challenge, $30 \mu \mathrm{g}$ of rOVA or rlipo-OVA was administered to the C57BL/6 mice. Tumor diameters were estimated in two orthogonal dimensions using an electronic caliper three times per week. Tumor volumes were calculated with the following formula: $\left(\right.$ length $\times$ width $\left.^{2}\right) \times 1 / 2$.

\section{Depleting subpopulations of $\mathrm{CD4}^{+}$or $\mathrm{CD8}^{+} \mathrm{T}$ lymphocytes in mice}

The experimental protocols of $\mathrm{T}$ cell depletion were modified from a previous study [52]. Briefly, groups of mice were treated intraperitoneally i.p. by injection with $0.5 \mathrm{mg}$ of the rat anti-mouse CD4 antibody (clone GK1.5, eBioscience) and rat anti-mouse CD8 antibody (clone 53-6.72, eBioscience) to deplete $\mathrm{CD}^{+}$or $\mathrm{CD}^{+}$ $\mathrm{T}$ lymphocytes, respectively. A total of $0.5 \mathrm{mg}$ of rat $\mathrm{IgG}$ (Invitrogen) was used as a control antibody in experiments. All antibodies were administered on the second day after the inoculation of $2 \times 10^{4} \mathrm{EG} 7$ tumor cells. On the third day after the tumor inoculation, $30 \mu \mathrm{g}$ of rlipo-OVA was subcutaneously injected into the C57BL/6 mice (six per group). The tumor volume was monitored by palpation and inspection.

\section{Depleting mice of CD127 T lymphocytes in a prophylactic model}

The experiments with CD127 T cell depletion have been described previously [34]. Briefly, the C57BL/6 mice were immunized twice by subcutaneous injection of rlipo-OVA $(30 \mu \mathrm{g})$ and PBS at one-week intervals. On day 17, immunized rlipo-OVA mice were treated i.p. $0.5 \mathrm{mg}$ of rat anti-mouse CD127 antibody (clone SB/14, $\mathrm{BD}$ Bioscience) to deplete $\mathrm{CD} 127^{+} \mathrm{T}$ lymphocytes or a rat anti-mouse IgG antibody (clone R35-95, BD Bioscience) as a control. A total of $2 \times 10^{4}$ EG7 tumor cells were inoculated on day 35 (six per group).

\section{Statistics}

All statistical analyses were performed with Prism (GraphPad Software, CA, USA). A two-tailed unpaired Student's $t$ test was performed on the data. $\mathrm{Ns}=$ no significant difference. Significant differences are represented as follows: ${ }^{*} p<0.05 ; *^{*} p<0.01 ; * * * p<0.001$.

\section{Abbreviations}

OVA, ovalbumin; rOVA, recombinant ovalbumin; rlipo-OVA, recombinant lipidated ovalbumin; APCs, antigen-presenting cells; CTL, cytotoxic T lymphocyte; $\mathrm{T}_{\mathrm{EM}}$, effector memory $\mathrm{T}$ cells; $\mathrm{T}_{\mathrm{CM}}$, central memory $\mathrm{T}$ cells. 


\section{ACKNOWLEDGMENT}

The authors would like to thank Dr. Wang-Chou Sung (National Institute of Infectious Diseases and Vaccinology, National Health Research Institutes, Taiwan) for providing rlipo-Nter [53].

\section{CONFLICTS OF INTEREST}

No potential conflicts of interest were disclosed.

\section{GRANT SUPPORT}

This work was supported by a grant from the National Health Research Institutes Taiwan (VC-PP-25 to C.-H.L.) and a grant from the National Science Council (NSC 101-2320-B-400-008-MY3 and NSC 101-2321-B-400-021-MY2 to C.-H.L. and NSC 1032321-B-400-008 to S.-J.L.).

\section{REFERENCES}

1. Palucka K, Banchereau J. Dendritic-Cell-Based Therapeutic Cancer Vaccines. Immunity. 2013; 39:38-48.

2. Andersen MH, Schrama D, Straten PT, Becker JC. Cytotoxic T cells. J Invest Dermatol. 2006; 126:32-41.

3. Jin B, Sun T, Yu XH, Yang YX, Yeo AE. The effects of TLR activation on T-cell development and differentiation. Clin Dev Immunol. 2012; 2012:836485.

4. Janssen EM, Droin NM, Lemmens EE, Pinkoski MJ, Bensinger SJ, Ehst BD, Griffith TS, Green DR, Schoenberger SP. CD4(+) T-cell help controls CD8(+) T-cell memory via TRAIL-mediated activation-induced cell death. Nature. 2005; 434:88-93.

5. Filipazzi P, Pilla L, Mariani L, Patuzzo R, Castelli C, Camisaschi C, Maurichi A, Cova A, Rigamonti G, Giardino F, Di Florio A, Asioli M, Frati P, et al. Limited induction of tumor cross-reactive $T$ cells without a measurable clinical benefit in early melanoma patients vaccinated with human leukocyte antigen class I-modified peptides. Clin Cancer Res. 2012; 18:6485-6496.

6. Reed SG, Bertholet S, Coler RN, Friede M. New horizons in adjuvants for vaccine development. Trends Immunol. 2009; 30:23-32.

7. Joffre OP, Segura E, Savina A, Amigorena S. Crosspresentation by dendritic cells. Nature reviews Immunology. 2012; 12:557-569.

8. Vyas JM, Van der Veen AG, Ploegh HL. The known unknowns of antigen processing and presentation. Nature reviews Immunology. 2008; 8:607-618.

9. Fehres CM, Unger WWJ, Garcia-Vallejo JJ, van Kooyk Y. Understanding the biology of antigen cross-presentation for the design of vaccines against cancer. Front Immunol. $2014 ; 5$.
10. Dresch C, Leverrier Y, Marvel J, Shortman K. Development of antigen cross-presentation capacity in dendritic cells. Trends Immunol. 2012; 33:381-388.

11. Datta SK, Redecke V, Prilliman KR, Takabayashi K, Corr M, Tallant T, DiDonato J, Dziarski R, Akira S, Schoenberger SP, Raz E. A subset of toll-like receptor ligands induces crosspresentation by bone marrow-derived dendritic cells. J Immunol. 2003; 170:4102-4110.

12. Wagner CS, Cresswell P. TLR and nucleotide-binding oligomerization domain-like receptor signals differentially regulate exogenous antigen presentation. J Immunol. 2012; 188:686-693.

13. de Brito C, Tomkowiak M, Ghittoni R, Caux C, Leverrier Y, Marvel J. CpG promotes cross-presentation of dead cellassociated antigens by pre-CD8 alpha $(+)$ dendritic cells. J Immunol. 2011; 186:1503-1511.

14. Oh JZ, Kedl RM. The capacity to induce cross-presentation dictates the success of a TLR7 agonist-conjugate vaccine for eliciting cellular immunity. J Immunol. 2010; 185:4602-4608.

15. Shen KY, Song YC, Chen IH, Leng CH, Chen HW, Li HJ, Chong P, Liu SJ. Molecular mechanisms of TLR2-mediated antigen cross-presentation in dendritic cells. J Immunol. 2014; 192:4233-4241.

16. Sallusto F, Geginat J, Lanzavecchia A. Central memory and effector memory T cell subsets: Function, generation, and maintenance. Annu Rev Immunol. 2004; 22:745-763.

17. Sallusto F, Lenig D, Forster R, Lipp M, Lanzavecchia A. Two subsets of memory $\mathrm{T}$ lymphocytes with distinct homing potentials and effector functions. Nature. 1999; 401:708-712.

18. Kaech SM, Wherry EJ, Ahmed R. Effector and memory T-cell differentiation: implications for vaccine development. Nature reviews Immunology. 2002; 2:251-262.

19. Budd RC, Cerottini JC, Horvath C, Bron C, Pedrazzini T, Howe RC, Macdonald HR. Distinction of virgin and memory lymphocytes-T stable acquisition of the pgp-1 glycoprotein concomitant with antigenic-stimulation. J Immunol. 1987; 138:3120-3129.

20. Hikono H, Kohlmeier JE, Ely KH, Scott I, Roberts AD, Blackman MA, Woodland DL. T-cell memory and recall responses to respiratory virus infections. Immunol Rev. 2006; 211:119-132.

21. Hendriks J, Gravestein LA, Tesselaar K, van Lier RAW, Schumacher TNM, Borst J. CD27 is required for generation and long-term maintenance of $\mathrm{T}$ cell immunity. Nat Immunol. 2000; 1:433-440.

22. Fritsch RD, Shen XL, Sims GP, Hathcock KS, Hodes RJ, Lipsky PE. Stepwise differentiation of CD4 memory T cells defined by expression of CCR7 and CD27. J Immunol. 2005; 175:6489-6497.

23. Ochsenbein AF, Riddell SR, Brown M, Corey L, Baerlocher GM, Lansdorp PM, Greenberg PD. CD27 expression promotes long-term survival of functional 
effector-memory CD8(+) cytotoxic T lymphocytes in HIVinfected patients. J Exp Med. 2004; 200:1407-1417.

24. Hikono H, Kohlmeier JE, Takamura S, Wittmer ST, Roberts AD, Woodland DL. Activation phenotype, rather than central-or effector-memory phenotype, predicts the recall efficacy of memory CD8(+) T cells. J Exp Med. 2007; 204:1625-1636.

25. Huster KM, Busch V, Schiemann M, Linkemann K, Kerksiek KM, Wagner H, Busch DH. Selective expression of IL-7 receptor on memory T cells identifies early CD40Ldependent generation of distinct CD8(+) memory T cell subsets. Proc Natl Acad Sci USA. 2004; 101:5610-5615.

26. Mikkelsen M, Holst PJ, Bukh J, Thomsen AR, Christensen JP. Enhanced and sustained CD8(+) T cell responses with an adenoviral vector-based Hepatitis $\mathrm{C}$ virus vaccine encoding NS3 linked to the MHC Class II chaperone protein invariant chain. J Immunol. 2011; 186:2355-2364.

27. Bachmann MF, Wolint P, Schwarz K, Jager P, Oxenius A. Functional properties and lineage relationship of CD8(+) $\mathrm{T}$ cell subsets identified by expression of IL-7 receptor alpha and CD62L. J Immunol. 2005; 175:4686-4696.

28. Appay V, Dunbar PR, Callan M, Klenerman P, Gillespie GMA, Papagno L, Ogg GS, King A, Lechner F, Spina CA, Little S, Havlir DV, Richman DD, et al. Memory CD8(+) T cells vary in differentiation phenotype in different persistent virus infections. Nat Med. 2002; 8:379-385.

29. Chen HW, Liu SJ, Liu HH, Kwok Y, Lin CL, Lin LH, Chen MY, Tsai JP, Chang LS, Chiu FF, Lai LW, Lian WC, Yang CY, et al. A novel technology for the production of a heterologous lipoprotein immunogen in high yield has implications for the field of vaccine design. Vaccine. 2009; 27:1400-1409.

30. Chiang CY, Liu SJ, Tsai JP, Li YS, Chen MY, Liu HH, Chong P, Leng CH, Chen HW. A Novel Single-Dose Dengue Subunit Vaccine Induces Memory Immune Responses. PLoS One. 2011; 6.

31. Kwok Y, Sung WC, Lin ALH, Liu HH, Chou FAH, Hsieh SSY, Leng CH, Chong P. Rapid isolation and characterization of bacterial lipopeptides using liquid chromatography and mass spectrometry analysis. Proteomics. 2011; 11:2620-2627.

32. Leng CH, Chen HW, Chang LS, Liu HH, Liu HY, Sher YP, Chang YW, Lien SP, Huang TY, Chen MY, Chou AH, Chong PL, Liu SJ. A recombinant lipoprotein containing an unsaturated fatty acid activates NF-kappa B through the TLR2 signaling pathway and induces a differential gene profile from a synthetic lipopeptide. Mol Immunol. 2010; 47:2015-2021.

33. Huang CY, Chen JJW, Shen KY, Chang LS, Yeh YC, Chen IH, Chong P, Liu SJ, Leng CH. Recombinant Lipidated HPV E7 Induces a Th-1-Biased Immune Response and Protective Immunity against Cervical Cancer in a Mouse Model. PLoS One. 2012; 7.

34. Kaech SM, Tan JT, Wherry EJ, Konieczny BT, Surh CD, Ahmed R. Selective expression of the interleukin 7 receptor identifies effector CD8 T cells that give rise to long-lived memory cells. Nat Immunol. 2003; 4:1191-1198.

35. de Titta A, Ballester M, Julier Z, Nembrini C, Jeanbart L, van der Vlies AJ, Swartz MA, Hubbell JA. Nanoparticle conjugation of $\mathrm{CpG}$ enhances adjuvancy for cellular immunity and memory recall at low dose. Proc Natl Acad Sci USA. 2013; 110:19902-19907.

36. Chua BY, Olson MR, Bedoui S, Sekiya T, Wong CY, Turner SJ, Jackson DC. The use of a TLR2 agonist-based adjuvant for enhancing effector and memory CD8 T-cell responses. Immunol Cell Biol. 2014; 92:377-383.

37. Olson JA, McDonald-Hyman C, Jameson SC, Hamilton SE. Effector-like CD8(+) T Cells in the Memory Population Mediate Potent Protective Immunity. Immunity. 2013; 38:1250-1260.

38. Cui WG, Joshi NS, Liu Y, Meng HL, Kleinstein SH, Kaech SM. TLR4 ligands lipopolysaccharide and monophosphoryl lipid: a differentially regulate effector and memory CD8(+) T cell differentiation. J Immunol. 2014; 192:4221-4232.

39. Van Duikeren S, Fransen MF, Redeker A, Wieles B, Platenburg G, Krebber WJ, Ossendorp F, Melief CJM, Arens R. Vaccine-induced effector-memory CD8(+) T cell responses predict therapeutic efficacy against tumors. J Immunol. 2012; 189:3397-3403.

40. Hervas-Stubbs S, Olivier A, Boisgerault F, Thieblemont N, Leclerc C. TLR3 ligand stimulates fully functional memory CD8(+) T cells in the absence of CD4(+) T-cell help. Blood. 2007; 109:5318-5326.

41. Lebel ME, Daudelin JF, Chartrand K, Tarrab E, Kalinke U, Savard P, Labrecque N, Leclerc D, Lamarre A. Nanoparticle adjuvant sensing by TLR7 enhances CD8(+) T cellmediated protection from listeria monocytogenes infection. J Immunol. 2014; 192:1071-1078.

42. Wirth TC, Xue HH, Rai D, Sabel JT, Bair T, Harty JT, Badovinac VP. Repetitive Antigen Stimulation Induces Stepwise Transcriptome Diversification but Preserves a Core Signature of Memory CD8(+) T Cell Differentiation. Immunity. 2010; 33:128-140.

43. Badovinac VP, Messingham KAN, Jabbari A, Haring JS, Harty JT. Accelerated CD8(+) T-cell memory and primeboost response after dendritic-cell vaccination. Nat Med. 2005; 11:748-756.

44. Woodland DL. Jump-starting the immune system: primeboosting comes of age. Trends Immunol. 2004; 25:98-104.

45. Roberts AD, Woodland DL. Cutting edge: Effector memory $\mathrm{CD} 8(+) \mathrm{T}$ cells play a prominent role in recall responses to secondary viral infection in the lung. J Immunol. 2004; 172:6533-6537.

46. Bridle BW, Clouthier D, Zhang L, Pol J, Chen L, Lichty BD, Bramson JL, Wan YH. Oncolytic vesicular stomatitis virus quantitatively and qualitatively improves primary CD8(+) T-cell responses to anticancer vaccines. Oncoimmunology. $2013 ; 2$. 
47. Shirota H, Sano K, Kikuchi T, Tamura G, Shirato K. Regulation of murine airway eosinophilia and Th2 cells by antigen-conjugated $\mathrm{CpG}$ oligodeoxynucleotides as a novel antigen-specific immunomodulator. J Immunol. 2000; 164:5575-5582.

48. BenMohamed L, Wechsler SL, Nesburn AB. Lipopeptide vaccines - yesterday, today, and tomorrow. Lancet Infect Dis. 2002; 2:425-431.

49. Moyle PM, Toth I. Self-adjuvanting lipopeptide vaccines. Curr Med Chem. 2008; 15:506-516.

50. Chentoufi AA, Nesburn AB, BenMohamed L. Recent advances in multivalent self adjuvanting glycolipopeptide vaccine strategies against breast cancer. Arch Immunol Ther Exp. 2009; 57:409-423.
51. Song YC, Cheng HY, Leng CH, Chiang SK, Lin CW, Chong P, Huang MH, Liu SJ. A novel emulsion-type adjuvant containing $\mathrm{CpG}$ oligodeoxynucleotides enhances CD8(+) T-cell-mediated anti-tumor immunity. J Control Release. 2014; 173:158-165.

52. Lin CC, Chou CW, Shiau AL, Tu CF, Ko TM, Chen YL, Yang BC, Tao MH, Lai MD. Therapeutic HER2/Neu DNA vaccine inhibits mouse tumor naturally overexpressing endogenous neu. Mol Ther. 2004; 10:290-301.

53. Song YC, Liu HH, Chen IH, Chen HW, Chong P, Leng $\mathrm{CH}$, Liu SJ. A purified recombinant lipopeptide as adjuvant for cancer immunotherapy. Biomed Res Int. 2014; 2014:349783. doi: 10.1155/2014/349783. 